\title{
DISTRIBUIÇÃO DE RECEPTORES IONOTRÓPICOS DE GLUTAMATO E SUA CO-LOCALIZAÇÃO COM A FOSFOPROTEÍNA NEURAL DARPP-32 NO CÓRTEX PRÉ-FRONTAL DE RATOS
}

Tese apresentada ao Programa de Pós-Graduação em Fisiologia Humana do Instituto de Ciências Biomédicas da Universidade de São Paulo, para obtenção do Título de Doutor em Ciências.

Área de concentração: Fisiologia Humana

Orientador: Prof. Dr. Martin Andreas Metzger

São Paulo

2009 


\section{RESUMO}

SAMBE, N. A. Distribuição de receptores ionotrópicos de glutamato e sua colocalização com a fosfoproteína neural DARPP-32 no córtex pré-frontal de ratos. 2009. Tese (Doutorado em Fisiologia). - Instituto de Ciências Biomédicas, Universidade de São Paulo, São Paulo, 2009.

O córtex pré-frontal medial $(\mathrm{PFCm})$ é caracterizado por entradas glutamatérgicas e dopaminérgicas que muitas vezes convergem sobre os mesmos neurônios alvos. Existe uma extensa literatura de trabalhos eletrofisiológicos e moleculares que mostram que a estimulação de receptores de dopamina (DA) do tipo D1 facilita a neurotransmissão glutamatérgica em neurônios piramidais do PFCm e apontam para um importante papel da fosfoproteína DARPP-32 na mediação dessas interações. Em contraste, só ha escassa informação a respeito da base anatômica das interações DA - glutamato (Glu) no PFCm. Assim, investigamos nesse estudo, através de técnicas de marcação simples de imunoperoxidase primeiramente a distribuição das mais comuns subunidades dos receptores de Glu do tipo AMPA (GluR1, GluR2, GluR2/3, GluR4), NMDA (NMDAR1) e kainato (GluR5/6/7) e depois através de métodos de dupla-marcação de imunofluorescência a co-localização dessas subunidades entre-se, com a fosfoproteína DARPP-32, assim como marcadores de interneurônios. Nossos resultados mostram uma distinta distribuição laminar no PFCm de alguns das subunidades investigadas. As subunidades GluR2 e GluR2/3 são as mais amplamente distribuídas no PFCm, enquanto as subunidades GluR1 e GluR4 mostram uma distribuição esparsa. Os principais resultados que obtivemos através dos nossos estudos de co-localização são: (1.) todos os neurônios positivos DARPP-32 também expressam as subunidades GluR2/3; (2.) receptores de Glu do tipo AMPA, NMDA e kainato são amplamente co-localizados em neurônios piramidais no PFCm; (3.) as subunidades GluR1 e GluR4 são principalmente expressas em neurônios GABAérgicos. Resumido, nossos resultados indicam que os neurônios piramidais e interneurônios do PFCm diferem quanto à combinação das subunidades do tipo AMPA expressas. Enquanto GluR2 e GluR2/3 são amplamente expressas em neurônios piramidais do PFCm, GluR1 e GluR4 parecem ser preferencialmente expressas em interneurônios. O fato que receptores de Glu do tipo AMPA e NMDA são amplamente co-expressos com a DARPP-32 em neurônios piramidais do PFCm, torna os neurônios DARPP-32+ candidatos privilegiados para processos de neuroplasticidade como a LTP.

Palavras-chave: Neurotransmissores. Córtex pré-frontal. Dopamina. Glutamato. DARPP-32. AMPA. 


\begin{abstract}
SAMBE, N. A. Distribution of ionotropic glutamate receptors and their colocalization with the phosphoprotein DARPP-32 in the medial prefrontal córtex of rats. 2009. Doctoral thesis (Physiology) - Instituto de Ciências Biomédicas, Universidade de São Paulo, São Paulo, 2009.
\end{abstract}

The medial prefrontal cortex (PFCm) is characterized by glutamatergic and dopaminergic inputs that often converge on the same target cells. There is a bulk of electrophysiological and molecular studies demonstrating that the stimulation of dopamine (DA) D1 receptors facilitates glutamatergic neurotransmission in pyramidal neurons of the PFCm and indicating an important role for the neuronal phosphoprotein DARPP-32 as a mediator of these interactions. In contrast, there is only limited information about the anatomical bases of DA - glutamate (Glu) interactions in the PFCm. For this purpose, we investigated in the present study using immunoperoxidase techniques first the distribution of the most common AMPA (GluR1, GluR2, GluR2/3, GluR4), NMDA (NMDAR1), and kainate (GluR5/6/7) type Glu receptor subunits and second by double-immunofluorescence techniques the co-localization of these subunits with each other, with the phosphoprotein DARPP -32, as well as markers of interneurons. Our results show a distinct laminar distribution of some of the subunits investigated. The subunits GluR2 and Glur2/3 are the most widely distributed within the PFCm, whereas GluR1 and GluR4 show a more restricted distribution. The main findings obtained in our co-localization studies are: (1.) all DARPP-32+ neurons also express the GluR2/3 subunits; (2.) Glu receptors of the AMPA, NMDA, and kainate type are widely co-localized in pyramidal neurons of the PFCm; (3.) the GluR1 and GluR4 subunits are preferentially expressed in interneurons. These findings indicate that pyramidal neurons and interneurons of the PFCm differ with respect to the combination of AMPA type subunits expressed. Whereas GluR2 and GluR2/3 are widely expressed in pyramidal neurons of the PFCm, GluR1 and GluR4 seem to be preferentially expressed in interneurons. The fact that AMPA and NMDA receptors are commonly co-expressed with DARPP-32 in pyramidal neurons of the PFCm, turns the DARPP-32+ neurons privileged candidates for neuroplasticity processes such as LTP.

Key words: Neurotransmitters. Prefrontal cortex. Dopamine. Glutamate. DARPP-32. AMPA. 


\section{INTRODUÇÃO}

O córtex cerebral é organizado de maneira hierárquica. No arranjo da organização cortical se encontram áreas sensoriais e motoras primárias e secundárias, relacionadas com funções sensoriais e motoras específicas e áreas associativas mais elevadas, com maior desenvolvimento filogenético e ontogenético, relacionadas com as funções integrativas (FUSTER, 1997). Atualmente, considerase que o córtex pré-frontal (PFC) em primatas e humanos tenha atingido o mais alto grau de desenvolvimento filogenético (UYLINGS e VAN EDEN, 1990). Tem sido proposto que essa área cortical se encontra no topo da hierarquia sensório-motora e se destina à integração de informações sensoriais de todas as modalidades para a representação e execução de ações (PASSINGHAM, 1993; FUSTER, 1997; FUSTER, 2001). A função integrativa do PFC é refletida no padrão de sua conectividade. O PFC possui poucas conexões diretas com áreas sensoriais primárias e com o córtex motor primário, entretanto é densamente conectado com áreas associativas de todas as modalidades sensoriais, com estruturas límbicas, como a amígdala e o hipocampo, o núcleo médiodorsal do tálamo (MD) e com estruturas motoras, como os gânglios da base e o córtex pré-motor (GROENEWEGEN 1988; SESACK et al., 1989; CONDÉ et al., 1995; GROENEWEGEN e UYLINGS, 2000; HEIDBREDER e GROENEWEGEN 2003).

Estudos de lesão em primatas e ratos têm indicado que o PFC, em particular sua região medial (PFCm), participa dos aspectos mais complexos da seleção, ordenação e seqüenciamento comportamental, ou seja, na organização temporal de complexas seqüências de comportamentos direcionados a um objetivo (FUSTER 1997; DALLEY et al., 2004). Um dos principais mecanismos discutidos como sendo subjacente a essas funções é a capacidade do PFC em reter traços de memória de curta duração, referida como memória de trabalho ("working memory"), com base nas informações do mundo externo (GOLDMAN-RAKIC 1990; 1995; KESNER, 2000; REPOVS e BADDELEY, 2006). Esse distinto tipo de memória, principalmente associado a áreas pré-frontais, tem se mostrado criticamente dependente de um balanceamento perfeito do sistema dopaminérgico no PFC (BROZOSKI et al., 1979; SAWAGUCHI e GOLDMAN-RAKIC 1991). O direcionamento do comportamento pelo PFC também é claramente dependente de traços de distintas memórias de longa duração, armazenadas principalmente em áreas do sistema límbico, e acessíveis ao 
PFC através de suas ricas interconexões com essas estruturas. $O$ último conceito sobre o funcionamento do PFC foi referido como "trabalhando com memória" ("working with memory") por Schacter, (1994).

O PFCm em rato também tem sido associado a diversas outras funções cognitivas, incluindo mecanismos de atenção, tomada de decisões e associações ação-recompensa (DALLEY et al., 2004). Além disso, em particular a subárea mais ventral do PFCm, o córtex infra-límbico (IL), é claramente envolvido em várias funções víscero-motoras (NEAFSEY, 1990).

\subsection{Anatomia do córtex pré-frontal}

O PFC de mamíferos tem sido descrito e classificado através de diversos critérios anatômicos, tais como a citoarquitetura (BRODMANN, 1909), a conectividade com o núcleo médiodorsal do tálamo (ROSE e WOOLSEY 1948; KRETTEK e PRICE 1977a; GROENEWEGEN, 1988; RAY e PRICE, 1992), e a presença de uma inervação dopaminérgica proveniente do mesencéfalo ventral (THIERRY et al, 1973; UYLINGS e VAN EDEN, 1990; WILLIAMS e GOLDMANRAKIC, 1998).

Os estudos clássicos de Brodmann (1909) foram baseados principalmente em critérios citoarquitetônicos (características agranular versus granular). Em primatas, - PFC pode ser delineado pela presença de uma camada cortical IV bastante proeminente. Outros mamíferos, incluindo muitos roedores, não possuem uma camada IV bem delineada nas áreas frontais do córtex cerebral. Em ratos, uma camada granular IV é ausente em todas as áreas consideradas como pertencentes ao PFC (KRETTEK e PRICE, 1977a; VAN EDEN e UYLINGS, 1985; GROENEWEGEN, 1988). A ausência de outros critérios anatômicos ou funcionais para definir o PFC levou, no passado, a diferentes visões, e em alguns casos controvérsias sobre a existência e extensão do PFC em mamíferos não primatas, particularmente em ratos (PREUSS, 1995; UYLINGS et al, 2003; WISE, 2008). Recentemente, se tornou consenso geral que todos os mamíferos possuem um PFC, e que uma combinação de critérios anatômicos e funcionais deve ser considerada para a definição do PFC em diferentes espécies de animais. Atualmente, a definição mais usada para essa área cortical é a que considera o PFC como principal alvo cortical comum das fibras oriundas do núcleo médiodorsal do 
tálamo e das fibras dopaminérgicas provenientes da área tegmental ventral (VTA) do mesencéfalo (UYLINGS e VAN ÉDEN, 1990, UYLINGS et al., 2003).

Baseado nesses critérios, o PFC do rato pode ser subdividido em três divisões principais (Fig. 1). Primeiro, uma região medial, o PFC medial que ocupa quase toda a parede medial do córtex rostral e dorsal ao joelho do corpo caloso. $O$ presente trabalho focou a região medial do PFC. O PFCm, por sua vez, consiste de pelo menos quatro subáreas distintas. Essas são, de dorsal para ventral, o córtex pré-central medial (PrCm), o córtex do cingulado anterior ( $\mathrm{AC})$, o córtex pré-límbico (PL) e o córtex infra-límbico (IL). Segundo, a região localizada ventralmente ao PFCm, denominada de PFC orbital (PFCo), que ocupa a superfície inferior do pólo frontal, dorsal ao tubérculo olfatório (TO). O PFCo também consiste de pelo menos cinco subáreas, denominadas de medial para lateral, de córtex orbital medial (MO), córtex orbital ventral (VO), córtex orbital ventro-lateral (VLO) e córtex orbital lateral (LO). Imediatamente na porção dorsal do LO encontra-se ainda uma região do córtex orbital, referida como córtex orbital dorso-lateral (DLO). O DLO se diferencia do LO por sua camada cortical II mais densa (RAY e PRICE, 1992).

Rostralmente ao PFCm e PFCo no pólo frontal do hemisfério cerebral, situase o córtex polar frontal, que é subdividido em partes medial e lateral. O córtex polar frontal medial (FPm) substitui $O \mathrm{MO}, \mathrm{PL}$ e $\mathrm{AC}$ e apresenta características citoarquitetônicas semelhantes às do PL. O córtex polar frontal lateral (FPI) é semelhante ao DLO tanto em termos de projeções tálamo-corticais como em termos de citoarquitetura (RAY e PRICE, 1992). Terceiro, uma região cortical lateral, denominada de córtex pré-frontal lateral (PFCl), que ocupa a área da ínsula agranular e pode ser subdividida em córtex da ínsula agranular ventral (Alv), córtex da ínsula agranular dorsal (Ald), rostralmente localizado, e o córtex da ínsula agranular posterior (Alp), situado mais caudalmente (VAN De WERD e UYLINGS, 2008). Algumas áreas, como córtex da ínsula desgranular (DI), são consideradas suplementares ao PFC. O DI se situa dorsalmente ao Ald, entre este e o córtex da ínsula granular (GI) (CECHETTO e SAPER, 1987). 

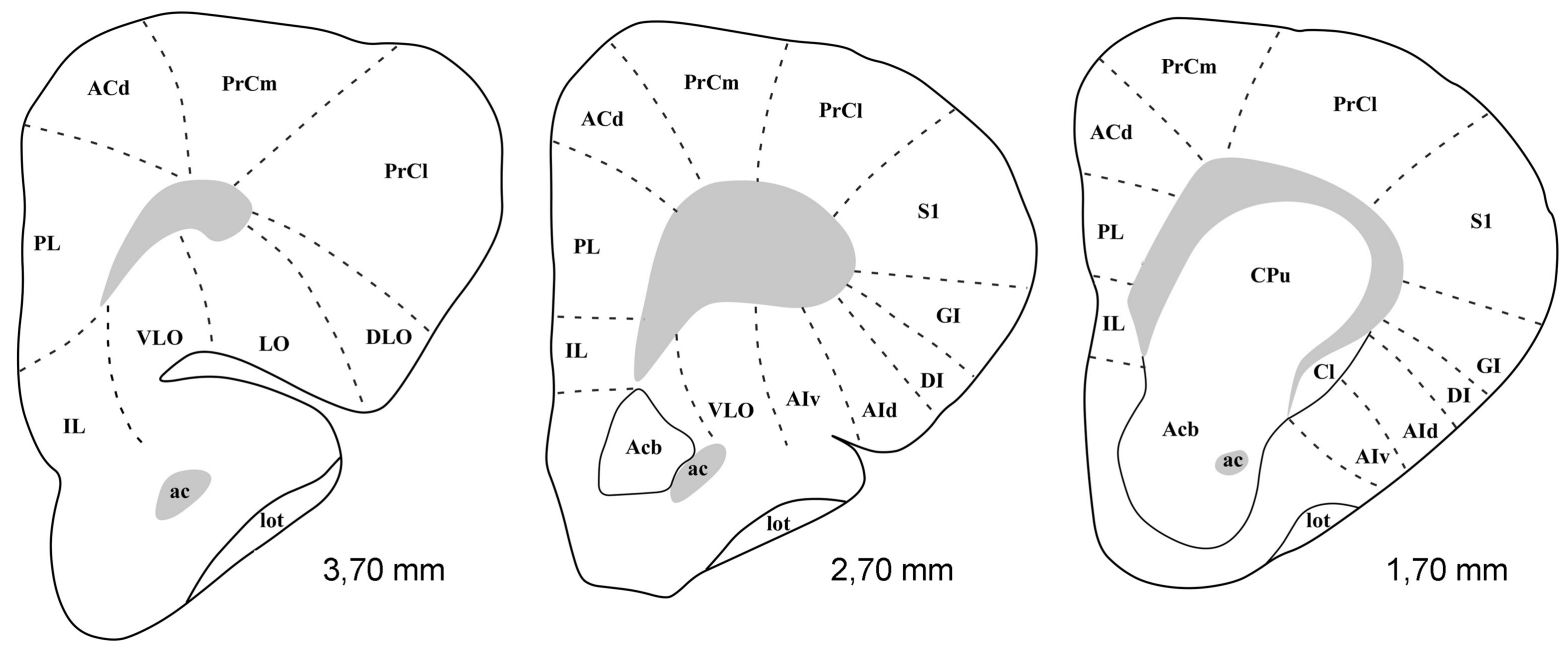

Figura 1 - Desenhos de cortes coronais do encéfalo do rato ao nível do PFC. A figura ilustra aproximadamente os três níveis ao longo do eixo rostro-caudal do PFC nos quais foram realizadas as análises quantitativas. Os valores indicam o nível a partir do Bregma. Consultar lista de abreviaturas, para abreviações.

\subsection{Conectividade do PFC}

Como descrito acima, o PFCm do rato consiste de várias subregiões citoarquitetonicamente distintas. Essas áreas podem ser claramente diferenciadas com base nos distintos padrões de conexões aferentes e eferentes com outras áreas corticais e estruturas subcorticais.

\subsubsection{Conexões com o tálamo}

Conexões tálamo-corticais têm sido usadas como importante critério para definir o PFC em diferentes espécies. Desde os estudos clássicos de Rose e Woolsey (1948), sabe-se que o MD inerva densamente o PFC em diferentes espécies. Estudos subsequentes tornaram evidente que diferentes segmentos do $M D$ enviam eferências topograficamente organizadas para diferentes subáreas do PFC (LEONHARD, 1969; KRETTEK e PRICE, 1977a; GROENEWEGEN, 1988; HURLEY et al., 1991; RAY e PRICE, 1992). As conexões entre o PFC e o MD são recíprocas, e o PFC envia extensas projeções de volta para o tálamo que não são restritas ao MD (SESACK et al., 1989; VERTES, 2002; RAY et al., 1992). As projeções córtico-talâmicas estão topograficamente organizadas a partir de um gradiente ventro-dorsal no PFCm para um gradiente médio-lateral no tálamo dorsal. Nesse sentido, as projeções pré-frontais mediais envolvem principalmente a linha 
média, os núcleos ânteromedial e médiodorsal e os núcleos intralaminares. O IL e a parte ventral do PL (PLv) na divisão ventral do PFCm alcançam principalmente os núcleos da linha média e o segmento medial do $\mathrm{MD}$, enquanto que a parte dorsal do PL (PLd), o ACd e o PrCm na divisão dorsal do PFCm se projetam para o segmento lateral do MD e os núcleos intralaminares (GROENEWEGEN e UYLINGS, 2000; VERTES, 2002). As projeções córtico-talâmicas se originam predominantemente da camada VI, enquanto as projeções recíprocas oriundas do MD são principalmente direcionadas para a camada III e V do PFCm (RAY et al., 1992; KURODA et al., 1995; ROTARU et al., 2005). Além do MD, vários núcleos do grupo da linha média e dos núcleos intralaminares projetam densamente para o PFC (VAN der WERF et al., 2002; HOOVER e VERTES, 2007). Atualmente, existem amplas evidências de que todas as conexões entre o tálamo e PFC usam o glutamato (Glu) como neurotransmissor (RAY et al., 1992; FREMEAU et al., 2004).

\subsubsection{Conexões com o cerne límbico}

O PFC recebe importantes aferências glutamatérgicas de estruturas do cerne límbico (HEIMER e VAN HOESEN, 2006), em especial do hipocampo e do complexo amigdalóide basal. Essas estruturas estão predominantemente conectadas com subáreas na divisão ventral do PFCm, embora partes específicas da amígdala também inervem as subáreas na divisão dorsal do PFCm. As relações do PFCm com a formação hipocampal (próprio hipocampo e subículo) são em geral unidirecionais. Densas projeções hipocampais originadas do subículo e da área CA1 são direcionadas diretamente para o IL e PL (JAY e WITTER, 1991; SWANSON, 1981; CARR e SESACK, 1996; GABBOTT et al., 2002; HOOVER e VERTES, 2007), enquanto, escassas fibras pré-frontais alcançam diretamente a formação hipocampal (SESACK et al., 1989; HURLEY et al., 1991). A maioria das projeções do PFC alcança indiretamente a formação hipocampal, via córtex entorrinal ou via talâmica (VERTES, 2006, 2007). As conexões entre o PFCm e o córtex parahipocampal são bi-direcionais. Por sua vez, o córtex peririnal projeta principalmente para o IL e PLv, enquanto que a área entorrinal dorso-lateral alcança todo o PFCm (VAN EDEN et al., 1992; DELATOUR e WITTER, 2002, HOOVER e VERTES, 2007).

As projeções do PFCm para o córtex entorrinal se originam predominantemente do 
IL, enquanto que o PL, ACd e PrCm enviam densas projeções para o córtex peririnal (SESACK et al., 1989; HURLEY et al., 1991).

As projeções da amígdala para o PFCm se originam principalmente da divisão caudal do complexo amigdalóide basal, e em menor grau no córtex periamigdalóide (KRETTEK e PRICE, 1977b; MCDONALD, 1987; McDONALD, 1991). As projeções oriundas do complexo amigdalóide para o PFCm exibem um evidente arranjo topográfico (CASSELL e WRIGHT, 1986). Assim, as partes caudais do núcleo basal parvicelular projetam primariamente para as camadas profundas do IL e do PL ventral, enquanto que a parte caudal do núcleo basal acessório projeta para grande parte do PFCm, incluindo particularmente o IL e o PL e, em menor grau, o ACd e PrCm (KRETTEK e PRICE, 1977b; PETROVICH et al., 1996). As conexões do PFCm com o complexo amigdalóide são recíprocas e mais densas do que as conexões com o hipocampo. Desta forma, o IL se projeta para os seguintes núcleos: lateral capsular, central, medial, acessório basal e núcleo amigdalóide cortical (HURLEY et al., 1991; McDONALD, 1991; McDONALD et al., 1996). A parte ventral do PL apresenta um padrão de distribuição muito semelhante ao do IL, enquanto que a divisão dorsal do $\mathrm{PL}$, assim como o $\mathrm{ACd}$, alcançam apenas regiões restritas dos núcleos basal e lateral e, em menor grau, o núcleo central da amígadala. 0 PrCm envia fibras para as mesmas restritas regiões da amígdala, envolvendo principalmente o núcleo central (SESACK et al., 1989; McDONALD, 1996; McDONALD, 1998).

\subsubsection{Conexões córtico-corticais}

Outra característica do PFCm é a sua riqueza de conexões córtico-corticais. Vários estudos com traçadores retrógrados e anterógrados demonstraram que as distintas subáreas do PFCm estão interconectadas principalmente com áreas secundárias de todas as modalidades sensoriais, assim como com áreas sensóriomotoras (SEESACK et al., 1989; REEP et al., 1990; VAN EDEN et al., 1992; CONDÉ et al., 1995; HEIDBREDER e GROENEWEGEN, 2003; VERTES et al., 2004; HOOVER e VERTES, 2007). Grande parte dessas conexões estão organizadas topográficamente com as diferentes subáreas do PFCm, estabelecendo conexões específicas. Em suma, pode ser constatada uma subdivisão principal no PFCm em um componente dorsal, que abrange o PrCm, ACd e a parte dorsal do PL (PLd), e 
um componente ventral que abrange a parte ventral do PL (PLv), o IL e o MO (HEIDBREDER e GROENEWEGEN, 2003). Assim, as regiões dorsais do PFCm (PrCm e ACd) apresentam principalmente interconexões com áreas corticais sensório-motoras e associativas, e por isso têm sido implicadas em vários comportamentos motores, enquanto que a região ventral do PFCm (IL e PL) apresenta principalmente interconexões com o córtex temporal e outros córtices associativos límbicos, sendo assim, associada a vários processos relacionados à emoção, cognição e memória (VAN EDEN et al., 1992; HOOVER e VERTES, 2007).

\subsubsection{Conexões com o estriado}

Como o resto do manto cortical, o PFC envia eferências topograficamente organizadas para o estriado em ratos (SEESACK et al., 1989; McGEORGE e FAULL, 1989; BERENDSE et al., 1992; REEP et al., 2003) e macacos (HABER et al., 2000). No estriado dorsal, cada uma das distintas subáreas do PFC possui um campo terminal longitudinal distinto que mostra certo grau de convergência com os campos terminais de áreas adjacentes (BERENDSE et al., 1992). As áreas préfrontais, em conjunto com as áreas pré-motoras, encontram-se numa posição única pelo fato de somente elas não apenas se projetarem para os gânglios da base, mas também receberem informações do estriado, via diferentes complexos circuitos de retro-alimentação chamados circuitos gânglios da base-tálamo-corticais (ALEXANDER et al., 1990; GROENEWEGEN et al., 1997). As eferências do PFCm não são restritas ao estriado dorsal, mas também alcançam de maneira topográfica o núcleo acumbens (Acb) no estriado ventral. O subterritório medial do Acb, denominado concha, recebe principalmente entradas do IL, enquanto as eferências do PL são mais direcionadas para a parte lateral do Acb, denominada cerne (BERENDSE et al., 1992; BROG et al., 1993; WRIGHT e GROENEWEGEN, 1995).

\subsubsection{Conexões com grupos celulares dopaminérgicos do mesencéfalo}

Além das conexões com o tálamo, o PFCm do rato é caracterizado por uma densa inervação dopaminérgica (THIERRY et al., 1973; VAN EDEN et al., 1987; KALSBEEK et al., 1988). Em ratos, a inervação dopaminérgica do PFC se origina principalmente da VTA (grupo A10), que dá origem ao sistema mesocorticolímbico 
da dopamina (DA; ver BJÖERKLUND e DUNETT, 2007), o qual em ratos, inerva principalmente o PFC, o núcleo acumbens (Acb) e a amígdala. Em um grau muito menor, a substância negra compacta (SNc; grupo A9) também contribui para as projeções dopaminérgicas para o PFC (DIVAC et al., 1978; FALLON, 1981; SWANSON, 1982; FALLON e LOUGHLIN 1982; CONDÉ et al., 1995). O núcleo retrorrubral (grupo A8) parece não contribuir para a inervação dopaminérgica do PFCm em ratos (DEUTCH et al., 1988). Diferentemente, as projeções mesopréfrontais em macacos mostram uma origem muito mais ampla, com todos os grupos dopaminérgicos do mesencéfalo (A8, $A 9, A 10)$ contribuindo substancialmente para essas projeções (WILLIAMS e GOLDMAN-RAKIC 1998). Além do componente dopaminérgico, existem também projeções GABAérgicas da VTA para o PFCm em ratos (CARR e SESACK, 2000a) e macacos (WILLIAMS e GOLDMAN-RAKIC, 1998). Em geral, foi observada uma tendência para uma topografia invertida nas projeções da VTA para o PFC. Nesse sentido, neurônios dopaminérgicos localizados nas divisões dorsais da VTA inervam predominantemente sítios no PFCm ventral, enquanto que os neurônios localizados na VTA ventral projetam preferencialmente para a divisão dorsal do PFCm (DEUTCH, 1993).

Interessantemente, o PFCm parece ser uma das poucas áreas corticais que não só recebe aferências, mas que também eferenta a VTA e SNc (SESACK et al., 1989; CARR e SESACK, 2000b; GABBOTT et al., 2005). A via do PFC para a VTA parece ser muito seletiva na medida em que as eferências do PFC se dirigem preferencialmente para neurônios dopaminérgicos que projetam para o PFC e neurônios GABAérgicos que projetam para o núcleo acumbens (CARR e SESACK, 2000b).

Estudos de imuno-eletrônica conduzidos em diversas áreas corticais, incluindo o PFC de diferentes espécies, têm mostrado que os axônios dopaminérgicos contatam preferencialmente espinhos e hastes dendríticas, e em menor grau, os corpos celulares de neurônios piramidais (VAN EDEN et al., 1987; SMILEY et al., 1992; SMILEY e GOLDMAN-RAKIC, 1993). Apenas uma minoria dos terminais axônicos dopaminérgicos contatam interneurônios GABAérgicos (SESACK et al., 1995). A grande maioria das sinapses formadas pelos terminais dopaminérgicos é do tipo simétrica, entretanto, ocorrem também sinapses dopaminérgicas assimétricas (VAN EDEN et al., 1987; SMILEY et al., 1992; SMILEY e GOLDMAN-RAKIC, 1993). Nem todos os terminais dopaminérgicos, no entanto, 
parecem formar sinapses morfologicamente definidas. Existem evidências de que além da neurotransmissão sináptica, a DA também pode agir através da neurotransmissão volumétrica (DESCARRIES et al., 1996; PASPALAS e GOLDMAN-RAKIC, 2004).

Uma peculiaridade importante é que as sinapses dopaminérgicas nos espinhos e hastes dendríticas freqüentemente são encontradas imediatamente ao lado de sinapses assimétricas supostamente formadas por terminais glutamatérgicos. Essa condição característica tem sido descrita em diversas áreas corticais e estriatais em diversas espécies (FREUND et al., 1984; SMILEY et al., 1992; SMILEY e GOLDMAN-RAKIC, 1993; METZGER et al., 2002). Partindo da observação dessas "tríades sinápticas" foi postulado que a DA deve preferencialmente modular as entradas glutamatérgicas nos neurônios piramidais (SMILEY et al., 1992; SMILEY e GOLDMAN-RAKIC, 1993; GOLDMAN-RAKIC, 1995).

\subsubsection{Conexões com outras estruturas subcorticais}

Além de entradas dopaminérgicas provenientes da VTA, o PFC recebe outras aferências monoaminérgicas, incluindo densas projeções serotonérgicas oriundas principalmente do núcleo dorsal da rafe (VERTES, 1991) e projeções menos densas noradrenérgicas do lócus cerúleos (FOOTE et al., 1983). Interessantemente, como no caso da VTA, o PFC é uma das poucas áreas corticais que projetam de volta para o núcleo dorsal da rafe (PEYRON et al., 1998; GABBOTT et al., 2005; GONÇALVES et al., 2009) e lócus cerúleos (LUPPI et al., 1995; LEE et al., 2005). O PFCm também recebe aferências colinérgicas do telencéfalo basal oriundas principalmente da região da banda diagonal de Broca (SAPER, 1984), assim como outras projeções colinérgicas do núcleo tegmental látero-dorsal (LDT) do tegmento mesopontino (SATOH e FIBINGER, 1986; HOOVER e VERTES, 2007). Além disso, o PFCm está reciprocamente conectado com o hipotálamo (SESACK et al., 1989; FLOYD et al., 2001; SAPER, 1985) e projeta principalmente através das suas subáreas ventrais para vários centros autonômicos subcorticais (SESACK et al., 1989; GABBOTT et al., 2005). 


\subsection{Neuroquímica do PFCm}

Como detalhado acima, as entradas glutamatérgicas e dopaminérgicas são essenciais para caracterizar anatomicamente e funcionalmente o PFC. Em seguida, são apresentados dados anatômicos, fisiológicos e funcionais desses dois importantes sistemas de neurotransmissores, assim como de seus receptores e das principais cascatas de sinalização intracelulares que medeiam seus efeitos.

\subsubsection{Glutamato}

O glutamato (Glu) é atualmente considerado o neurotransmissor excitatório mais amplamente distribuído no sistema nervoso dos mamíferos (FREMEAU et al., 2004; WATKINS e JANE, 2006). Esse aminoácido é provavelmente a substância transmissora usada na maioria das sinapses no cérebro, sozinho ou em conjunto com neuropeptídeos e outros compostos neuro-ativos com os quais é co-localizado. Assim, Glu medeia a grande maioria da neurotransmissão excitatória rápida necessária para o processamento de informação no cérebro (BROMAN, 2000). Além disso, mecanismos glutamatérgicos estão criticamente envolvidos em processos de neuroplasticidade como a potenciação (LTP) e depressão (LTD) de longo prazo (BLISS e COLLINGRIDGE, 1993; MALENKA e NICOLL, 1999; MALENKA e BEAR, 2004).

O efeito excitatório do Glu no cérebro foi reconhecido pela primeira vez na década de 50 por Hayashi (1954) e Curtis e Watkins (1960), entretanto, apenas alguns anos depois Glu foi aceito como tendo função de neurotransmissor. Diferentemente da maioria dos outros neurotransmissores que são sintetizados apenas por neurônios que os usam como neurotransmissores, o Glu está presente em todas as células, exercendo também papel na síntese protéica, no metabolismo intermediário e como constituinte das proteínas (FREMEAU et al., 2001). Devido às altas concentrações e a distribuição ubíqua de Glu encontradas no cérebro e outros tecidos, tornou-se difícil distinguir o Glu com função de neurotransmissor do Glu usado no metabolismo celular.

Novas técnicas de imuno-eletrônica desenvolvidas por Storm-Mathisen e colaboradores (1983) permitiram pela primeira vez a identificação de Glu em sinapses, e assim uma distinção entre Glu usado como neurotransmissor e Glu 
usado no metabolismo celular. Porém, só a recente descoberta e caracterização de uma família de transportadores vesiculares de Glu (VGLUT 1-3) abriram a possibilidade de uma identificação inequívoca das vias glutamatérgicas no cérebro. Anticorpos seletivos contra esses transportadores permitem uma marcação seletiva de "clusters" de vesículas nas vias caracterizadas como glutamatérgicas (TAKAMORI et al., 2000; FREMEAU et al., 2001). Esses estudos comprovaram que o Glu é, como previamente assumido, usado como principal neurotransmissor em grande parte do sistema eferente neocortical, incluindo as conexões córticotalâmicas, córtico-corticais, córtico-estriatais, e córtico-espinais. O Glu medeia suas ações no SNC dos mamíferos via ativação de uma grande variedade de receptores ionotrópicos (ligantes dos canais iônicos de cátions) e metabotrópicos (acoplados a proteínas Gs) (KEW e KEMP, 2005).

\subsubsection{Receptores ionotrópicos de glutamato}

Estudos bioquímicos e neurofarmacológicos identificaram três grandes famílias (Fig. 2) de receptores íonotrópicos de Glu (iGluRs), que são designados de acordo com o primeiro agonista ativado de forma seletiva, sendo assim denominados de N-metil-D-aspartato (NMDA), ácido a-amino-3-hidroxi-5-metil4-isoxazol propiônico (AMPA) e 2-carboxi-3-carboximetil-4-isopropenilpirrolidina (Kainato). O receptor nativo em todas essas famílias parece um tetrâmero, composto na maioria dos casos de mais de um tipo de subunidade. Em geral, as subunidades dos receptores ionotrópicos de Glu apresentam alta identidade de seqüências de aminoácidos e homologias entre si (DINGLEDINE et al., 1999; MAYER e ARMSTRONG, 2004). 


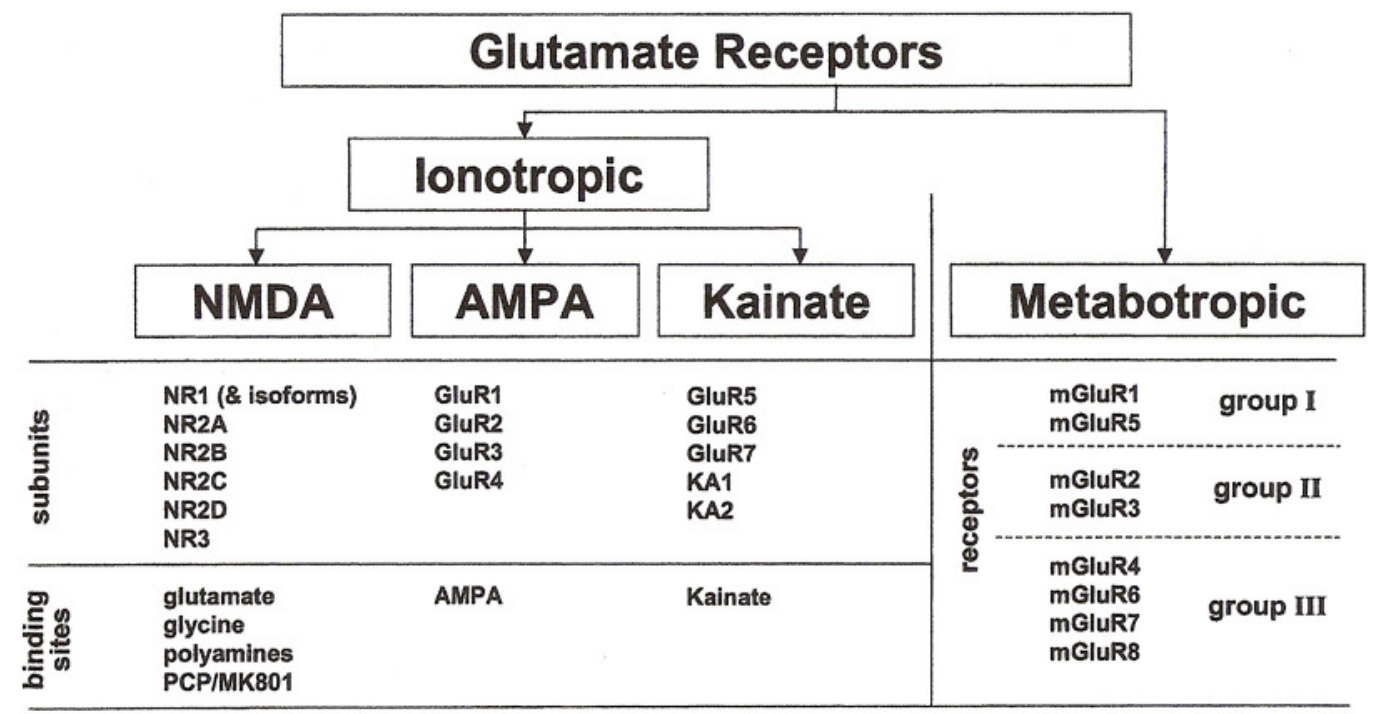

Figura 2 - Classificação dos subtipos de receptores de glutamato. O esquema foi adaptado de Meador-Woodroff e Kleinman (2002).

\subsubsection{Receptores do tipo AMPA}

A maioria dos receptores do tipo AMPA são tetrâmeros heteroméricos compostos por quatro subunidades GluR1 a GluR4 (ou GluRA-D) que são codificadas por genes separados e combinam-se em diferentes estequiometrias para formar tetrâmeros funcionais (HOLLMANN e HEINEMANN, 1994; DINGLEDINE et al., 1999; KEW e KEMP, 2005; CULL-CANDY et al., 2006; GREGER, 2007). Cada subunidade possui um grande domínio N-terminal extracelular, três domínios transmembrana e um domínio C-terminal intracelular. As subunidades GluR possuem alta identidade bioquímica entre si, divergindo particularmente no domínio C-terminal intracelular. O C-terminal dessas subunidades é crítico para a regulação da função do receptor AMPA. Muitos receptores AMPA contêm a subunidade GluR2, que desempenha um papel central na determinação da permeabilidade dos receptores heteroméricos ao $\mathrm{Ca}^{2+}$. Assim, os receptores AMPA que não contêm a subunidade GluR2 são permeáveis ao $\mathrm{Ca}^{2+}$ e exibem uma marcada retificação linear resultante de um bloqueio voltagem dependente do canal iônico pela poliamina intracelular (BOWIE e MAYER, 1995), enquanto heterômeros contendo pelo menos uma subunidade GluR2 são impermeáveis ao $\mathrm{Ca}^{2+}$. O aminoácido arginina, localizado em um sítio crítico no poro da alça no domínio m2, parece determinar a impermeabilidade ao $\mathrm{Ca}^{2+}$ em receptores do tipo AMPA que contém a subunidade 
GluR2. Nas outras subunidades esse sítio é ocupado pela glutamina (DINGLEDINE et al., 1999; SEEBURG e HARTNER, 2003). A composição das subunidades dos receptores do tipo AMPA varia de acordo com o tipo celular, desenvolvimento e região do cérebro.

Vários estudos têm examinado a distribuição das diferentes subunidades dos receptores de Glu do tipo AMPA no córtex de mamíferos, em particular ratos e macacos, pelas técnicas de "hibridização in situ" (CONTI et al. 1994; KONDO et al., 1997) e imunohistoquímica (PETRALIA e WENTHOLD, 1992; VICKERS et al., 1993; CONTI et al., 1994; HOF et al., 1996; PETRALIA et al., 1997). Porém, a grande maioria desses estudos descreveu a distribuição no córtex em geral (PETRALIA e WENTHOLD, 1992; PETRALIA et al., 1997) ou foi conduzido no córtex somatosensorial primário (CONTI et al. 1994; KONDO et al., 1997). Assim, poucos estudos focam a distribuição de receptores do tipo AMPA no PFCm, sendo o único deles realizado em macacos (VICKERS et al., 1993). Em geral, todos os estudos citados acima demonstraram que neurônios corticais exibem um marcado grau de heterogeneidade em relação à composição e número das subunidades dos receptores do tipo AMPA. A grande maioria dos estudos aponta as subunidades GluR2/3 como as mais amplamente distribuídas no córtex cerebral. Em contraste, as subunidades GluR1, e em particular GluR4, foram demonstradas como sendo as menos abundantemente distribuídas (PETRALIA e WENTHOLD, 1992; CONTI et al., 1994; KONDO et al., 1997). Os estudos de imunohistoquímica também apontaram que a grande maioria dos neurônios GluR2/3-positivos (+) é composta de neurônios piramidais, enquanto que a maioria das células GluR1+ e GluR4+ apresentam características morfológicas de células não-piramidais (PETRALIA e WENTHOLD, 1992; CONTI et al., 1994; KHARAZIA et al., 1996; PETRALIA et al., 1997).

\subsubsection{Receptores do tipo NMDA}

Até o presente são conhecidos sete genes separados que codificam para as subunidades do receptor de NMDA: NR1, NR2A, NR2B, NR2C, NR2D e NR3A e NR3D. Além disso, muitas variantes de "splicing" alternativos funcionais e não funcionais também foram identificadas (McBAIN e MAYER, 1994). Do ponto de vista molecular, as subunidades dos receptores NMDA apresentam alta identidade de seqüências de aminoácidos e homologias entre si (KUTSUWADA et al., 1992; ISHII 
et al., 1993). A subunidade NR1 é essencial para o funcionamento do receptor. Assim, um receptor do tipo NMDA funcional precisa ser composto de subunidades NR1 combinado com pelo menos uma subunidade NR2, ou de NR1 combinado com NR2 e NR3. A co-expressão da subunidade NR1 com uma ou mais subunidades de NR2 confere distintas propriedades funcionais e farmacológicas semelhantes às observadas no receptor nativo (KUTSUWADA et al., 1992; MONYER et al., 1992). Assim, o requerimento mínimo para um receptor de NMDA funcional é um arranjo tetramérico de dímeros de subunidades NR1 e NR2 (SCHORGE e COLQUHOUN, 2003; MAYER e ARMSTRONG, 2004). A subunidade NR3 parece não formar um receptor de NMDA funcional quando expressa apenas em combinação com NR1 ou NR2. Entretanto, a combinação heteromérica das três subunidades forma um receptor funcional (NISHI et al., 2001; SASAKI et al., 2002).

O receptor do tipo NMDA é o único receptor ionotrópico que requer dois ligantes, contendo sítios de ligação para a glicina e sítios para o Glu, localizados nas subunidades NR1 (KURYATOV et al., 1994; WAFFORD et al., 1995; KEW et al., 2000) e NR2, respectivamente (LAUBE et al., 1997; ANSON et al., 1998). Estudos eletrofisiológicos também têm demonstrado que a ativação dos receptores NMDA requer a ocupação tanto dos sítios da glicina como os do Glu (BENVENISTE e MAYER, 1991; CLEMENTS e WESTBROOK,1991). Outra característica importante do receptor do tipo NMDA é que sua atividade é altamente dependente de voltagem. Em estado de potencial de repouso, o canal se encontra bloqueado pelo $\mathrm{MG}^{2+}$ (NOVAK et al., 1984; WOLLMUTH et al., 1998), e a remoção deste só ocorre quando a membrana fica despolarizada (BLISS e COLLINGRIDGE, 1993).

Estudos de hibridização "in situ" e imunohistoquímica em ratos (MONYER et al., 1994; RUDOLF et al., 1996), macacos e humanos (HOF et al., 1996; HUNTLEY et al., 1997, CONTI et al., 1999) demonstraram que os receptores de Glu do tipo NMDA estão amplamente distribuídos no córtex cerebral, onde estão preferencialmente expressos em neurônios piramidais. Todos esses estudos apontaram que entre as subunidades dos receptores de NMDA conhecidas, a subunidade NR1 é a mais amplamente distribuída. Análises quantitativas de hibridizações "in situ" indicaram que a subunidade NR1 é expressa em quase todos os neurônios do sistema nervoso central, enquanto que as subunidades NR2A, NR2B, NR2C e NR2D mostraram uma distribuição mais restrita e também diferencial durante o desenvolvimento (MONYER et al., 1994). Estudos de imunohistoquímica no córtex cerebral de macacos 
(HUNTLEY et al., 1997) e humano (CONTI et al., 1999) revelaram que neurônios NMDAR1 + estão presentes em todas as áreas neocorticais examinadas. Estudos de imunoeletrônica no córtex cerebral de humanos mostraram intensa marcação para a subunidade NR1 nos dendritos e espinhos dendríticos, mas também evidenciaram marcação em terminais de axônios e em processos gliais (CONTI et al., 1999).

\subsubsection{Receptores do tipo kainato}

Cinco genes separados codificam para as diferentes subunidades dos receptores de kainato: GluR5, GluR6, e GluR7, assim como KA1 e KA2. O receptor nativo parece ser um tetrâmero que pode ser formado tanto pela combinação homomérica como pela combinação heteromérica dessas subunidades. (KEW e KEMP, 2005). Enquanto as combinações apenas de subunidades KA1 ou KA2 não formam um receptor funcional, a combinação dessas subunidades com GluR 5-7 parecem formar o receptor nativo (BLEAKMAN et al., 2002). Entretanto, na ausência das subunidades KA, as subunidades GluR 5-7 podem, por si só, formar receptores homoméricos de kainato funcionais, tal como ocorre na combinação das diferentes subunidades. Assim como as subunidades dos receptores do tipo AMPA, GluR 5, 6 e 7 estão sujeitos a "splicing" alternativo e "editing" de RNA que podem introduzir novas isoformas (DINGLEDINE et al., 1999). A composição precisa do receptor do kainato, no entanto, ainda não está definitivamente determinada (KEW e KEMP, 2005).

Além dos receptores ionotrópicos de Glu, oito tipos de receptores metabotrópicos de Glu acoplados à proteína G foram identificados (mGlu 1-8). Com base em suas seqüências de aminoácidos, seus acoplamentos a diferentes sistemas de segundo mensageiros e seus perfis farmacológicos, eles foram divididos em três grupos; Grupo I (mGluR1 e mGluR5); grupo II (mGluR2 e mGluR3) e grupo III (mGluRs 4, 6, 7, 8) (ver KEW e KEMP, 2005). Variantes de "splicing" alternativo também foram identificadas entre os receptores metabotrópicos de Glu (PIN et al., 2003). Os receptores metabotrópicos de Glu não foram tema do presente trabalho. 


\subsubsection{Dopamina}

A DA é a catecolamina predominante no cérebro e controla uma variedade de funções, incluindo atividade locomotora, cognição, emoção, ingestão de alimentos, mecanismos de recompensa e regulação endócrina (JAY, 2003; SEAMANS e YANG, 2004). Hoje em dia, a DA é o neurotransmissor mais investigado, em particular por causa do seu envolvimento em doenças como a doença de Parkinson (PD), esquizofrenia e quadros de hiperatividade (WEINBERGER et al., 1988; ABIDARGHAM et al., 2002; IVERSEN e IVERSEN, 2007). Além disso, mecanismos dopaminérgicos contribuem para as ações de reforços naturais (KELLEY e BERRIDGE, 2002) e drogas de abuso (DI CHIARA e IMPERATO, 1988). Porém, atualmente existe um debate intenso sobre o exato papel da DA em mecanismos de recompensa (BERRIDGE e ROBINSON, 1998; SPANAGEL e WEISS, 1999; UNGLESS, 2004; SCHULTZ 2007). A DA é um regulador chave para mecanismos de plasticidade sináptica, incluindo a LTP e a LTD, e está envolvida em vários aspectos da formação de memória (FREY et al., 1990., JAY, 2003). No PFC, a neurotransmissão dopaminérgica é crucial para uma cognição normal (BROZOSKI et al., 1979; WILLIAMS e CASTNER, 2006), e particularmente receptores de DA do tipo D1 são críticos para um perfeito funcionamento da memória de trabalho (WILLIAMS e GOLDMAN-RAKIC, 1995; MULLER et al., 1998).

Um papel especifica da DA como neurotransmissor foi primariamente proposto por Carlson e colaboradores $(1957,1958)$ na Suécia. Eles descobriram que os efeitos acinéticos da reserpina poderiam ser revertidos pela DOPA, a precursora da DA e noradrenalina, e foram relacionados com a recuperação das concentrações de DA, mas não de noradrenalina. Logo em seguida foi descoberto que o estriado contém uma rica inervação dopaminérgica (BERTLER e ROSENGREN, 1959; SANO et al., 1959), dando evidências para um papel desse novo neurotransmissor no controle de funções motoras. Ehringer e Hornykiewicz (1960) então descobriram que as concentrações de DA são altamente reduzidas em pacientes com PD, e estimularam assim os primeiros testes com L-DOPA como tratamento em pacientes de PD (BIRKMAYER E HORNYKIEWICZ, 1961). O novo método de histofluorescência de catecolaminas desenvolvido por Falck e Hlillarp (CARLSSON et al., 1962; FALCK et al., 1982) permitiu pela primeira vez a visualização e mapeamento de grupamentos de neurônios monoaminérgicos no cérebro 
(DAHLSTRÖM e FUXE, 1964). Com os avanços da técnica de imunohistoquímica e a introdução de anticorpos específicos contra a tirosina hidroxilase (TH), a enzima crítica para a síntese de DA, e anticorpos contra a própria DA (GEFFARD et al., 1984), foi pela primeira vez possível distinguir as diferentes catecolaminas e refinar 0 mapeamento das células dopaminérgicas no cérebro (HÖFKELT et al., 1984). Atualmente, está estabelecido que a inervação dopaminérgica do telencéfalo consiste de dois ou três sistemas dopaminérgicos ascendentes distintos (BJÖRKLUND e LINDVALL, 1984) oriundos de células dopaminérgicas nos grupos A8, A9, e A10 do mesencéfalo (BJÖRKLUND e DUNNETT, 2007). Enquanto a inervação dopaminérgica do estriado (sistema mesostriatal) tem sua origem principalmente na SN (grupo A9), o córtex (sistema mesocortical) e áreas límbicas como a amígdala (sistema mesolímbico) são inervados principalmente pela VTA (grupo A10) (SWANSON; 1982; FALLON e LOUGHLIN, 1982). No SNC a DA medeia as suas ações complexas atuando sobre pelo menos cinco diferentes subtipos de receptores de DA, todos receptores metabotrópicos acoplados a proteínas Gs (MISSALE et al., 1998).

\subsubsection{Receptores de dopamina}

O primeiro passo para a demonstração de receptores específicos para a DA foi dado através de estudos bioquímicos mostrando que a DA estimula a adenilil ciclase (AC) no cérebro (KEBABIAN et al., 1972). Alguns anos depois foi primariamente proposto através de estudos farmacológicos e bioquímicos que existem duas populações diferentes de receptores de DA uma estimulando a AC e a outra inibindo a AC (SPANO et al., 1978). Esses dois subtipos de receptores foram então chamados receptores do tipo D1 (aqueles que estimulam a AC) e D2 (aqueles que não são acoplados a AC) (KEBABIAN e CALNE, 1979). Estudos subseqüentes identificaram três outros membros da família dos receptores de DA: D3, D4 e D5. Atualmente existe consenso que os subtipos D1 e D5 formam juntos a subfamília dos receptores de DA do tipo D1, enquanto os subtipos D2, D3, e D4 formam a subfamília dos receptores do tipo D2 (MISSALE et al., 1998, WERKMAN, 2006). Avanços para a demonstração de receptores de DA no cérebro foram obtidos com o desenvolvimento de ligantes radioativos para os receptores do tipo D1 e D2 (SEEMAN, 1975; CREESE et al., 1976; LIDOW et al., 1991) e finalmente de 
anticorpos contra esses receptores (LEVEY et al., 1993; MULY et al., 1998; WANG e PICKEL, 2002). Através de estudos de receptor autoradiografia e imunohistoquímica, a maioria deles conduzidos em macacos, emerge o seguinte padrão da distribuição de receptores de DA do tipo D1 e D2 no PFC. Enquanto receptores do tipo D2 são apenas fracamente expressos no PFC (NEGYESSY e GOLDMAN-RAKIC, 2005), receptores do tipo D1 são moderadamente expressos em dendritos e espinhos de neurônios piramidais nas camadas I-III e V-VI (LIDOW et al., 1991; SMILEY et al., 1994). Porém, os ligantes radioativos mais usados (LIDOW et al., 1991) assim como muitos anticorpos (comunicações pessoais de Anita Aperia e Virginia Pickel) contra distintos tipos de receptores de DA ainda sofrem com problemas de especificidade.

Como mencionado acima, todos os diferentes subtipos de receptores de DA são receptores metabotrópicos acoplados a proteínas Gs. Isso significa que a ligação do neurotransmissor ao receptor não abre imediatamente (em torno de milisegundos) canais iônicos presente na membrana da célula pós-sináptica como no caso da neurotransmissão rápida, mediada por receptores que formam o próprio canal iônico como por exemplo os receptores ionotrópicos de Glu e os receptores do tipo GABA A. A neurotransmissão, mediada por receptores metabotrópicos como as de DA é muito mais complexa e demorada já que o neurotransmissor age primeiro sobre proteínas Gs, enzimas, segundo mensageiros como a AMP cíclico (cAMP) e proteínas cinases dependentes de sistemas de segundo mensageiros. Assim, a neurotransmissão dopaminérgica é considerada como um exemplo típico de neurotransmissão sináptica demorada ("slow sinaptic transmisson") (GREENGARD, 2001). No caso da neurotransmissão dopaminérgica foi demonstrado que a ligação da DA aos seus receptores causa um aumento dos níveis de AMPc, ativação da proteína cinase $A(P K A)$ e fosforilação de fosfoproteínas. Entre as fosfoproteínas envolvidas, em particular uma denominada DARPP-32 parece crucial para mediar os efeitos da DA (GREENGARD et al., 1999; GREENGARD, 2001).

\subsubsection{DARPP-32}

A DARPP-32 é uma fosfoproteína modulada por DA e monofosfato cíclico de adenosina (AMPc), com um peso molecular de cerca de 32 kD (WALAAS et al., 1983; OUIMET et al., 1984). DARPP-32 é fosforilada pelo AMPc através de uma proteína cinase $A(P K A)$, em resposta à ativação do receptor de DA do tipo D1. Por 
outro lado, a proteína calcineurina, ativada pela estimulação do receptor de DA do tipo D2, desfosforila a DARPP-32 (NISHI et al., 1997, 1999a, b). No seu estado fosforilado (mas não no desfosforilado), a DARPP-32 é um potente inibidor da proteína fosfatase-1, a PP-1 (HEMMINGS et al., 1984). A PP-1 por sua vez, é uma das mais importantes fosfatases serina-treonina que controlam, no sistema nervoso central, o estado de fosforilação e a redução dinâmica de vários efetores da atividade fisiológica (Fig. 3), incluindo receptores de neurotransmissores, canais e bombas iônicas, além de fatores transcripcionais (GREENGARD et al., 1998; GREENGARD, 2001; SVENNINGSSON et al., 2004).

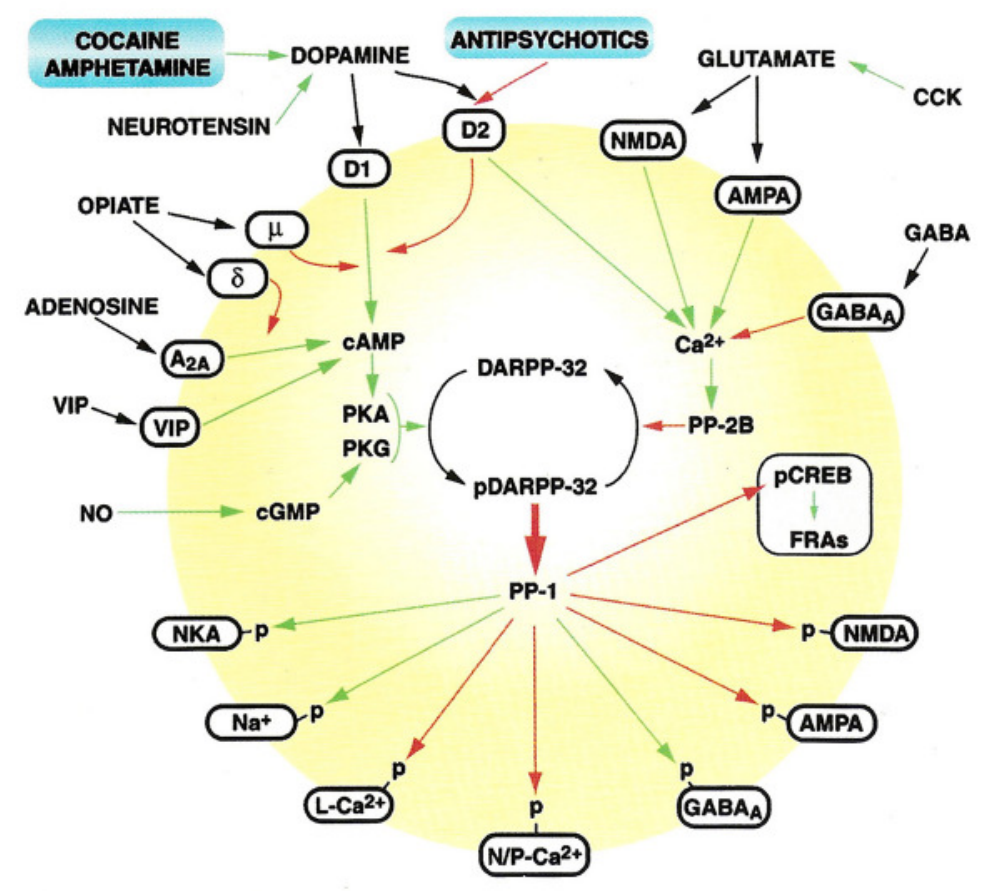

Figura 3 - Papel central da cascata DARPP-32/PP-1 em integrar vias de sinalização intracelulares ativados pela DA, o Glu e outros neurotransmissores. Ver texto da dissertação, para detalhes e abreviaturas. O esquema foi adaptado de Greengard e colaboradores (1999).

A distribuição da DARPP-32 foi estudada através de técnicas de imunohistoquímica no cérebro de ratos (OUIMET e GREENGARD, 1990a, b), primatas (BERGER et al., 1990; OUIMET et al., 1992), e aves (SCHNABEL et al., 1997). Em todas as espécies examinadas, a DARPP-32 foi demonstrada estar enriquecida nas regiões do cérebro que receberam densas aferências dopaminérgicas e em particular em regiões contendo receptores do tipo D1. Devido ao seletivo enriquecimento da DARPP-32 em neurônios dopaminoceptivos expressando o receptor D1, e sua regulação pela DA, acreditava-se inicialmente que 
a DARPP-32 seria principalmente envolvida com a neurotransmissão dopaminérgica mediada pelo receptor da DA do tipo D1. Por esta razão, a DARPP-32 tem também sido freqüentemente usada no passado em estudos neuroanatômicos como um marcador para neurônios que expressam receptores do tipo D1 (WALAAS e GREENGARD, 1984; OUIMET e GREENGARD, 1990b; BERGER et al., 1990; OUIMET et al., 1992). Estudos recentes de dupla-marcação no estriado dorsal (= caudado-putâmen; $\mathrm{CPu}$ ) de ratos mostraram que virtualmente todos os neurônios que expressam o receptor D1 também expressam DARPP-32 (LANGLEY et al., 1997). Entretanto, quase a metade dos neurônios DARPP-32 positivos (+) no CPu não mostrou expressão do receptor D1. Esse resultado fornece evidências adicionais de que a fosforilação da DARPP-32, não pode ser regulada exclusivamente pelos mecanismos mediados pelos receptores do tipo D1, mas também por mecanismos mediados pelos receptores do tipo D2 (NISHI et al., 1999b), e outros fatores além da DA (HALPAIN et al., 1990), incluindo a serotonina (SVENNINGSSON et al., 2002) e o Glu (NISHI et al., 2002, 2005).

Quase tudo do que se sabe a respeito do papel fisiológico da DA e da DARPP-32 é proveniente de estudos "in vivo" e "in vitro" feitos no CPu de mamíferos. As altas densidades de DA e DARPP-32 encontradas no CPu, assim como a grande homogeneidade neuronal desta estrutura, tem facilitado enormemente o estudo do papel funcional da DA e da DARPP-32, assim como das interações entre diferentes sistemas de neurotransmissores. Esses estudos em particular indicaram um papel chave da DARPP-32 na integração de vias de sinalização intracelulares ativadas pela DA e pelo Glu. Em todas as espécies examinadas a DARPP-32, assim como a DA, estão altamente enriquecidas no $\mathrm{CPu}$, núcleo acumbens e no tubérculo olfatório. Em torno de $95 \%$ de todos os neurônios no $\mathrm{CPu}$ são neurônios de projeção GABAérgicos que exibem uma morfologia neuronal similar e são referidos como neurônios espinhosos de tamanho médio (MSNs) (SMITH e BOLAM, 1990). Quase todos os MSNs (em torno de 96\%) contêm DARPP-32 (OUIMET et al., 1998). O restante das células neoestriatais são interneurônios sem espinhos, incluindo um tipo de tamanho grande que libera acetilcolina e não contém DARPP-32 (ANDERSON e REINER, 1991).

Com respeito aos receptores dopaminérgicos, os MSNs no CPu contêm tanto receptores da classe D1 quanto da classe D2. Essas duas subclasses de receptores de DA parecem largamente segregadas em duas subpopulações de MSNs 
(GERFEN, 1992; YUNG et al., 1995). Enquanto os receptores da classe D1 são expressos predominantemente em MSNs que se projetam para a substância negra e que co-expressam os neuropeptídeos dinorfina e substância $P$, receptores da classe D2 são predominantemente encontrados em MSNs que se projetam para o globo pálido e que co-expressam encefalina. Entretanto, recentes estudos demonstraram que uma parcela significante dos MSNs expressa tanto receptores da classe D1 quanto da classe D2 (SURMEIER et al., 1996; WONG et al., 1999; DENG et al., 2006). Além das ricas aferências dopaminérgicas vindas da substância negra e da área tegmental ventral, os MSNs recebem entradas excitatórias glutamatérgicas do córtex cerebral e do tálamo, assim como aferências GABAérgicas através de colaterais recorrentes (GERFEN, 1992b; SMITH et al., 1998). Os terminais glutamatérgicos agem tanto nos receptores de Glu do tipo NMDA como nos receptores do tipo AMPA (BERNARD et al., 1997; BERNARD e BOLAM, 1998). Quase todos os MSNs parecem conter a subunidade NR1 dos receptores de Glu do tipo NMDA (BERNARD e BOLAM, 1998), assim como as subunidades GluR2/3 dos receptores de Glu do tipo AMPA (BERNARD et al., 1997; DENG et al., 2007). Estudos de dupla-imunomarcação no CPu revelaram que mais de $80 \%$ das sinapses axoespinhosas imunopositivas para a subunidade NR1 também foram imunopositivas para GluR2/3. Entretanto, sinapses marcadas somente com GluR2/3 também foram detectadas (BERNARD e BOLAM, 1998). Interessantemente, a ativação dos receptores do tipo NMDA induziu desfosforilação da DARPP-32 em cortes de neoestriado do rato (HALPAIN et al., 1990). Estes resultados indicam que os efeitos opostos da DA e do Glu na excitabilidade de neurônios neoestriatais é refletido nos efeitos opostos destes neurotransmissores sobre 0 estado da fosforilação da DARPP-32, e que a desfosforilação da DARPP-32 pode ter também um papel importante na modulação da cascata DARPP/PP-1 (GREENGARD et al., 1999; NISHI 1999a). Estudos eletrofisiológicos e de microscopia eletrônica indicaram um papel complexo para a DA na modulação da neurotransmissão excitátoria mediada pelo Glu em MSNs (ver revisões de CEPEDA e LEVINE,1998; NICOLA et al., 2000, WEST e GRACE, 2003).

Recentes estudos bioquímicos e eletrofisiológicos em camundongos nos qual a expressão do gene para DARPP-32 foi suprimida ("knock-out") têm contribuído bastante para o entendimento do papel funcional da DARPP-32. Diversas alterações significativas nas respostas moleculares e comportamentais dependentes da DA, 
drogas de abuso, e medicamentos antipsicóticos foram descritas nesses animais "knock-out" (GREENGARD et al., 1998, 1999; FIENBERG et al., 1998; SVENNINGSSON et al., 2004). Entre outros efeitos importantes, esses estudos revelaram que a cascata DARPP-32/PP-1 está criticamente envolvida na regulação da fosforilação dos receptores de Glu dos tipos NMDA e AMPA. Assim, em cortes do tecido neuronal (slices) do núcleo acumbens de camundongos selvagens mantidos "in vivo", a DA aumenta normalmente em três ou quatro vezes a fosforilação da subunidade NR1 do receptor de Glu do tipo NMDA. Nos camundongos DARPP-32 "knock-out", esse efeito foi totalmente abolido (FIENBERG et al., 1998; GREENGARD et al., 1998). Além disso, as duas formas mais importantes de plasticidade sináptica, a LTP e a LTD são completamente abolidas em camundongos DARPP-32 "knockout” (CALABRESI et al., 2000).

Diferentemente do que ocorre com o neoestriado, muito pouco se sabe sobre a expressão das diferentes subunidades dos receptores de Glu do tipo AMPA e NMDA, assim como a expressão dos receptores de DA dos tipos D1 e D2, em neurônios DARPP-32+ no córtex cerebral. Um único estudo examinou a colocalização de receptores de Glu do tipo AMPA e NMDA com a DARPP-32 no córtex de ratos (WANG et al., 2004). Esses autores descreveram um alto grau de colocalização de DARPP-32 com as diferentes subunidades de receptores de Glu do tipo AMPA e NMDA no córtex e no CPu. Entretanto, em relação ao córtex, no estudo de Wang e colaboradores (2004), as áreas corticais nas quais a co-localização foi estudada não foram especificadas.

A distribuição da DARPP-32 no córtex cerebral tem sido investigada pela técnica de imunohistoquímica em ratos (OUIMET e GREENGARD, 1990b) e macacos (BERGER et al., 1990; QUIMET et al., 1992). Todos esses estudos investigaram a distribuição da DARPP-32 no córtex cerebral em geral, e nenhum deles foi focado no PFC. Os resultados desses estudos sugerem fortemente que embora a distribuição da DARPP-32 em áreas corticais não seja tão proeminente como no $\mathrm{CPu}$, parece existir um padrão típico de distribuição de neurônios DARPP32+ no córtex, que é comum a todas as espécies investigadas. Assim, na maioria das áreas corticais, neurônios DARPP-32+ mostraram um padrão bilaminar, com expressão moderada nas camadas II e III e expressão intensa nas camadas V e particularmente VI, enquanto a marcação para DARPP-32 é escassa ou ausente na camada IV. Além disso, a maior parte dos neurônios DARPP-32+ nesses estudos 
apresentou características morfológicas de células piramidais. No entanto, foram descritas diferenças importantes quanto à intensidade da imunomarcação para DARPP-32 entre diferentes populações de células piramidais.

O fato de que a grande maioria dos neurônios DARPP-32+ no córtex cerebral de mamíferos são células piramidais, assim como a sua distribuição laminar peculiar, claramente indica que a maioria dos neurônios DARPP-32+ deve ser composta de neurônios de projeção. Até o momento, isto foi demonstrado apenas para uma grande população de neurônios DARPP-32+ na camada VI do giro do cíngulo de ratos que manda projeções para o tálamo (OUIMET, 1991).

\subsubsection{Interações dopamina-glutamato}

Os primeiros indícios de uma real interação entre o sistema dopaminérgico e o sistema glutamatérgico vieram das observações ultra-estruturais acima referidas. Posteriormente, vários estudos eletrofisiológicos, realizados principalmente no neoestriado e no PFC, mostraram que a DA altera a resposta celular pós-sináptica para entradas glutamatérgicas de uma maneira altamente dependente dos tipos de receptores de Glu e DA envolvidos (CEPEDA et al., 1992, 1993). Estes estudos revelaram que a DA pode tanto excitar (CEPEDA et al., 1993) como inibir (CEPEDA et al., 1993; CALABRESI et al., 1997) as respostas das células pós-sinápticas induzidas pelo Glu. Foi postulado que estes resultados conflitantes podem ser devido ao fato de que a combinação concreta dos subtipos de receptores de Glu e DA envolvidos determina a direção da modulação subseqüente (CEPEDA et al., 1993). Estudos farmacológicos/eletrofisiológicos fortalecem esta hipótese (LEVINE et al., 1996) e atualmente a opinião mais aceita é a de que a DA potencializa as respostas evocadas pela ativação dos receptores de Glu do tipo NMDA e atenua as respostas evocadas pela ativação dos receptores de Glu do tipo AMPA (CALABRESI et al., 1997; CEPEDA e LEVINE, 1998b; NICOLA et al., 2000; FLORESHERNÁNDEZ et al., 2002; PRALONG et al., 2002). Além disso, foi demonstrado que o efeito da DA na excitabilidade de MSNs no CPu é também altamente dependente do valor do potencial da membrana destes neurônios, e deste modo também da complexa regulação de múltiplas condutâncias iônicas (WILSON e KAWAGUCHI, 1996). Também foi especificado que a potenciação de receptores do tipo NMDA depende criticamente da ativação dos receptores de DA do tipo D1 (WANG e 
O’DONNELL, 2001; FLORES-HERNÁNDEZ et al., 2002; CHEN et al., 2004), e que a ativação de receptores do tipo D2 produz efeitos opostos (WEST e GRACE, 2002). Em conjunto, todas essas observações indicam que a DA não deveria ser considerada um neurotransmissor clássico, com efeitos sempre inibitórios ou excitatórios, mas como um neuromodulador, cujas ações dependem de múltiplos fatores, particularmente da composição de receptores em suas células alvos (SESACK et al., 2003; SEAMANS e YANG, 2004).

Muitos estudos mostraram que as complexas interações bi-direcionais entre DA e Glu envolvem a ativação de cascatas de sinalização intracelulares e que a fosfoproteína DARPP-32 tem um papel chave na mediação dessas interações (GREENGARD et al., 1999). Recentemente, foi demonstrado no neoestriado (FLORES-HERNANDEZ et al., 2002) e no PFC (CHEN et al., 2004) que a DA e a DARPP-32 estão envolvidas tanto na modulação das correntes de receptores de Glu do tipo NMDA como na fosforilação da subunidade NR1 dos receptores de Glu do tipo NMDA (SNYDER et al., 1992), assim como na fosforilação da subunidade GluR1 dos receptores do tipo AMPA (SNYDER et al., 2000; HÅKANSON et al., 2006). Por outro lado, tem sido demonstrado que a ativação de receptores de Glu do tipo AMPA e NMDA diminui o estado de fosforilação de DARPP-32 mediado por proteínas fosfatases como a calcineurina e a proteína fosfatase-2A (NISHI et al., 2002).

Além disso, elegantes estudos ao nível molecular claramente indicam que receptores de neurotransmissores não são entidades estáticas, mas altamente dinâmicas, que podem ser inseridas ou retiradas da membrana pós-sináptica através dos mecanismos de endocitose e exocitose,assim como através da difusão lateral (COGNET et al., 2006). Em particular, os números de receptores de Glu do tipo AMPA podem ser rapidamente alterados nas sinapses em decorrência de fenômenos de neuroplasticidade como LTP e LTD (BREDT e NICOLL, 2003; KIM e SHENG, 2004; SHEPERD e HUGANIR 2007). Recentes estudos sugerem que interações entre a DA e o Glu não envolvem apenas a ativação de diversas cascatas de sinalização intracelular ativadas pelos dois tipos de neurotransmissores (NISHI et al., 2005), mas também ocorrem interações físicas diretas, proteína-proteína entre distintos tipos de receptores de DA e Glu que resultam na inserção de novos receptores nas membranas e sinapses (CEPEDA e LEVINE 2006; SCOTT e APERIA, 2009). Por exemplo, as duas regiões do domínio terminal-C dos receptores de DA do tipo D1 podem se acoplar fisicamente às subunidades NR1 e NR2A dos 
receptores de Glu do tipo NMDA, e assim seletivamente modular as funções dessas subunidades (LEE et al., 2002). A interação entre receptores de DA do tipo D1 e receptores de Glu do tipo NMDA parece funcionar de maneira bi-direcional, e envolve o deslocamento e inserção desses dois tipos de receptores em sinapses. Assim, numerosos estudos moleculares demonstraram que a ativação de receptores do tipo D1 pode afetar a localização subcelular de receptores do tipo NMDA (DUNAH e STANDAERT, 2001; DUNAH et al., 2004). Da mesma forma, tem sido demonstrado que a ativação de receptores do tipo NMDA aumenta o número de receptores do tipo D1 na superfície celular (PEI et al., 2004) e nos espinhos sinápticos (SCOTT et al., 2002, 2006). Esse aumento de receptores do tipo D1 nos espinhos envolve mudanças alostéricas no receptor do tipo NMDA, difusão lateral nas membranas dos receptores do tipo D1 e recrutamento desses receptores para espinhos sinápticos (SCOTT et al., 2006).

Atualmente, se torna cada vez mais evidente que distúrbios psiquiátricos como a esquizofrenia, assim como fenômenos como a dependência de drogas de abuso, que no passado foram atribuídos principalmente a mecanismos dopaminérgicos, também envolvem mecanismos glutamatérgicos e a interação entre esses dois sistemas de neurotransmissores. Recentes estudos comportamentais e de ressonância magnética revelaram que alterações adaptativas ao longo prazo na neurotransmissão glutamatérgica do PFC para o núcleo acumbens podem estar criticamente envolvidas em mecanismos de dependência (McFARLAND et al., 2003; KALIVAS, 2004; KALIVAS et al., 2005), fornecendo mais substrato para teorias integrativas sobre o fenômeno da dependência, que postulam circuitos e mecanismos comuns ou semelhantes para mecanismos de memória e dependência (KELLEY 2004; HYMAN et al., 2006; KALIVAS e O’BRIEN, 2008). De maneira similar, as principais teorias sobre a fisiopatologia da esquizofrenia deram uma guinada de teorias que implicam principalmente em uma hiperfunção do sistema dopaminérgico nessa enfermidade (CARLSSON e LINDQUIST, 1963; CARLSSON, 1977; SEEMAN e LEE, 1975; MELTZER e STAHL, 1976) para teorias mais abrangentes, implicando anormalidades em micro- e macrocircuitos do cérebro (WINTERER e WEINBERGER, 2004), e dando enfoque para a importância de interações entre os sistemas dopaminérgico, glutamatérgico e GABAérgico na fisiopatologia dessa doença (LARUELLE et al., 2003; CARLSSON, 2001; 2006; STONE et al., 2007). 
Em conjunto, todos esses dados mostram a enorme diversidade $\mathrm{e}$ complexidade das interações entre DA e Glu e sublinham um papel chave para a fosfoproteína DARPP-32 na integração dos efeitos da DA e do Glu em neurônios dopaminoceptivos. Conhecimentos detalhados a respeito da distribuição das principais subunidades dos receptores de Glu dos tipos AMPA, NMDA e kainato no PFC, e sobre o grau de co-localização dessas subunidades com a DARPP-32 e entre si, poderiam fornecer uma base anatômica para uma melhor compreensão das complexas interações DA - Glu no PFC. O fato de a DARPP-32 parecer ser expressa em todos os neurônios dopaminoceptivos fez da DARPP-32 uma ferramenta ideal para o estudo da co-localização de receptores de Glu em neurônios dopaminoceptivos. Esses conhecimentos poderiam também se tornar úteis para uma melhor compreensão de mecanismos de neuroplasticidade induzidos por aprendizagem ou uso de drogas de abuso no PFCm, assim como para o desenvolvimento de novas drogas terapêuticas. Tais drogas poderão virar agentes úteis no tratamento da esquizofrenia, diferentes formas de dependência de drogas de abuso e outras desordens neuropsiquiátricas que envolvem uma neurotransmissão dopaminérgica e glutamatérgica alterada no PFC. 


\section{CONCLUSÃO}

Nossos resultados mostram uma distinta distribuição laminar no $\mathrm{PFCm}$ de alguns das subunidades dos receptores de Glu investigadas e indicam que as subunidades GluR2 e GluR2/3 são as mais amplamente distribuídas no PFCm, enquanto as subunidades GluR1 e GluR4 exibem uma distribuição esparsa. Os principais resultados que obtivemos através dos nossos estudos de co-localização são que todos os neurônios positivos DARPP-32 também expressam as subunidades GluR2/3. Além disso, nos neurônios piramidais no $P F C m$, as subunidades GluR2/3 dos receptores de Glu do tipo AMPA são amplamente colocalizados com as subunidades NMDAR1 dos receptores de Glu de tipo NMDA e GluR5/6/7 dos receptores de Glu de tipo kainato. Em contraste, as subunidades GluR1 e GluR4 são principalmente expressas em interneurônios GABAérgicos.

Resumido, nossos resultados indicam que os neurônios piramidais e interneurônios do PFCm diferem quanto à combinação das subunidades do tipo AMPA expressas. Visto que DARPP-32 é um marcador confiável para neurônios que expressam receptores de DA do tipo D1, esses resultados indicam que receptores de Glu do tipo AMPA e NMDA são amplamente co-expressos com receptores de DA do tipo D1 em neurônios piramidais do PFC, o que torna os neurônios DARPP-32+ candidatos privilegiados para processos de neuroplasticidade como a LTP. 


\section{REFERÊNCIAS BIBLIOGRÁFICAS*}

ABI-DARGHAM, A.; MAWLAWI, O.; LOMBARDO, I.; GIL, R.; MARTINEZ, D.; HUANG, Y.; HWANG, D.R.; KEILP, J.; KOCHAN, L.; VAN HEERTUM, R.; GORMAN, J.M.; LARUELLE, M. Prefrontal dopamine D1 receptors and working memory in schizophrenia. J. Neurosci., v. 22, p. 3708-3719, 2002.

ALEXANDER, G.E.; CRUTCHER, M.D.; DELONG, M.R. Basal gangliathalamocortical circuits: parallel substrates for motor, oculomotor, "prefrontal" and "limbic" functions. Prog. Brain. Res., v. 85, p. 119-146, 1990.

ANDERSON, K.D.; REINER, A. Immunohistochemical localization of DARPP-32 in striatal projection neurons and striatal interneurons: implications for the localization of D1-like dopamine receptors on different types of striatal neurons. Brain Res., v. 568, p. 235-243, 1991.

ANSON, L.C.; CHEN, P.E.; WYLLIE, D.J.; COLQUHOUN, D.; SCHOEPFER, R. Identification of amino acid residues of the NR2A subunit that control glutamate potency in recombinant NR1/NR2A NMDA receptors. J. Neurosci., v. 18, p. 581-589, 1998.

BENVENISTE, M.; MAYER, M.L. Kinetic analysis of antagonist action at N-methyl-Daspartic acid receptors. Two binding sites each for glutamate and glycine. Biophys. J., v. 59, p. 560-573, 1991.

BERENDSE, H.W.; GALIS-DE GRAAF, Y.; GROENEWEGEN, H.J. Topographical organization and relationship with ventral striatal compartments of prefrontal corticostriatal projections in the rat. J. Comp. Neurol., v. 316, p. 314-347, 1992.

BERGER, B.; FEBVRET, A.; GREENGARD, P.; GOLDMAN-RAKIC, P.S. DARPP-32, a phosphoprotein enriched in dopaminoceptive neurons bearing dopamine D1 receptors: distribution in the cerebral cortex of the newborn and adult rhesus monkey. J. Comp. Neurol., v. 299, p. 327-348, 1990.

BERGER, B.; GASPAR, P.; VERNEY, C. Dopaminergic innervation of the cerebral cortex: unexpected differences between rodents and primates. Trends Neurosci., v. 14, p. 21-27, 1991.

BERNARD, V.; BOLAM, J.P. Subcellular and subsynaptic distribution of the NR1 subunit of the NMDA receptor in the neostriatum and globus pallidus of the rat: colocalization at synapses with the GluR2/3 subunit of the AMPA receptor. Eur. J. Neurosci., v. 10, p. 3721-3736, 1998.

BERNARD, V.; SOMOGYI, P.; BOLAM, J.P. Cellular, subcellular, and subsynaptic distribution of AMPA-type glutamate receptor subunits in the neostriatum of the rat. $\mathbf{J}$. Neurosci., v. 17, p. 819-833, 1997. 
BERRIDGE, K.C.; ROBINSON, T.E. What is the role of dopamine in reward: hedonic impact, reward learning, or incentive salience? Brain Res. Brain Res. Rev., v. 28, p. 309-369, 1998.

BERTLER, A.; ROSENGREN, E. Occurence and distribution of dopamine in the brain and other tissues. Experientia, v. 15, p. 10-11, 1959.

BIRKMAYER, W.; HORNYKIEWICZ, O. Der 1-Dioxyphenylalanin (I-Dopa) Effekt bei der Parkinson-Akinese. Wien Klin. Wochenschr., v. 73, p. 787-788, 1961.

BJORKLUND, A.; LINDVALL O. Dopamine-containing systems in the CNS. In: Björklund A.; Höfkelt T. (Ed.). Handbook of Chemical Neuroanatomy, Amsterdam: Elsevier, 1984. Vol. 2, p. 55-122.

BJORKLUND, A.; DUNNETT, S.B. Dopamine neuron systems in the brain: an update. Trends Neurosci., v. 30, p. 194-202, 2007.

BLEAKMAN, D.; GATES, M.R.; OGDEN, A.M.; MACKOWIAK, M. Kainate receptor agonists, antagonists and allosteric modulators. Curr. Pharm. Dês., v. 8, p. 873-885, 2002.

BLISS, T.V.; COLLINGRIDGE, G.L. A synaptic model of memory: long-term potentiation in the hippocampus. Nature, v. 361, p. 31-39, 1993.

BLISS, T.V.; LOMO, T. Long-lasting potentiation of synaptic transmission in the dentate area of the anaesthetized rabbit following stimulation of the perforant path. $\mathbf{J}$. Physiol., v. 232, p. 331-356, 1973.

BOWIE, D.; MAYER, M.L. Inward rectification of both AMPA and kainate subtype glutamate receptors generated by polyamine-mediated ion channel block. Neuron, $v$. 15, p. 453-462, 1995.

BREDT, D.S.; NICOLL, R.A. AMPA receptor trafficking at excitatory synapses. Neuron, v. 40, p. 361-379, 2003.

BRODMANN, K. Vergleichende Lokalisationslehre der Grosshirnhinde. Leipzig: Barth, 1909.

BROG, J.S.; SALYAPONGSE, A.; DEUTCH, A.Y.; ZAHM, D.S. The patterns of afferent innervation of the core and shell in the "accumbens" part of the rat ventral striatum: immunohistochemical detection of retrogradely transported fluoro-gold. $\mathbf{J}$.

Comp. Neurol., v. 338, p. 255-278, 1993

BROMAN, J.; HASSEL, B.; RINVIK, E.; OTTERSEN, O.P. Biochemistry and anatomy of transmitter glutamate. In: OTTERSEN, O.P.; STORM-MATHISEN, J. (Ed.). Handbook of chemical neuroanatomy. Amsterdam: Elsevier, 2000. Vol. 18, p. 144. 
BROSE, N.; HUNTLEY, G.W.; STERN-BACH, Y.; SHARMA, G.; MORRISON, J.H.; HEINEMANN, S.F. Differential assembly of coexpressed glutamate receptor subunits in neurons of rat cerebral cortex. J. Biol. Chem., v. 269, p. 16780-16784, 1994.

BROZOSKI, T.J.; BROWN, R.M.; ROSVOLD, H.E.; GOLDMAN, P.S. Cognitive deficit caused by regional depletion of dopamine in prefrontal cortex of rhesus monkey. Science, v. 205, p. 929-932, 1979.

CALABRESI, P.; GUBELliNI, P.; CENTONZE, D.; PICCONI, B.; BERNARDI, G.; CHERGUI, K.; SVENNINGSSON, P.; FIENBERG, A.A.; GREENGARD, P. Dopamine and CAMP-regulated phosphoprotein $32 \mathrm{kDa}$ controls both striatal long-term depression and long-term potentiation, opposing forms of synaptic plasticity. $\mathbf{J}$. Neurosci., v. 20, p. 8443-8451, 2000.

CALABRESI, P.; PISANI, A.; CENTONZE, D.; BERNARDI, G. Synaptic plasticity and physiological interactions between dopamine and glutamate in the striatum. Neurosci. Biobehav. Rev., v. 21, p. 519-523, 1997.

CARLSSON, A. Does dopamine play a role in schizophrenia? Psychol. Med., v. 7, p. 583-597, 1977.

CARLSSON, A.; LINDQVIST, M. Effect of chlorpromazine or haloperidol on the formation of 3-methoxytyramine and normetanephrine in mouse brain. Acta Pharmacol., v. 20, p. 140-44, 1963.

CARLSSON, A.; CARLSSON, M.L. A dopaminergic deficit hypothesis of schizophrenia: the path to discovery. Dialogues Clin. Neurosci., v. 8, p. 137-142, 2006.

CARLSSON, A.; FALCK, B.; HILLARP, N.A. Cellular localization of brain monoamines. Acta Physiol. Scand. Suppl., v. 56, p. 1-28, 1962.

CARLSSON, A.; LINDQVIST, M.; MAGNUSSON, T. 3,4-Dihydroxyphenylalanine and 5-hydroxytryptophan as reserpine antagonists. Nature, v. 180, p. 1200, 1957.

CARLSSON, A.; LINDQVIST, M.; MAGNUSSON, T.; WALDECK, B. On the presence of 3-hydroxytyramine in brain. Science, v. 127, p. 471, 1958.

CARLSSON, A.; WATERS, N.; HOLM-WATERS, S.; TEDROFF, J.; NILSSON, M.; CARLSSON, M.L. Interactions between monoamines, glutamate, and GABA in schizophrenia: new evidence. Annu. Rev. Pharmacol. Toxicol., v. 41, p. 237-260, 2001.

CARR, D.B.; SESACK, S.R. Hippocampal afferents to the rat prefrontal cortex: synaptic targets and relation to dopamine terminals. J. Comp. Neurol., v. 369, p. 1$15,1996$.

CARR, D.B.; SESACK, S.R. GABA-containing neurons in the rat ventral tegmental area project to the prefrontal cortex. Synapse, v. 38, p. 114-123, 2000a. 
CARR, D.B.; SESACK, S.R. Projections from the rat prefrontal cortex to the ventral tegmental area: target specificity in the synaptic associations with mesoaccumbens and mesocortical neurons. J. Neurosci., v. 20, p. 3864-3873, 2000b.

CARROLL, R.C.; BEATTIE, E.C.; VON ZASTROW, M.; MALENKA, R.C. Role of AMPA receptor endocytosis in synaptic plasticity. Nat. Rev. Neurosci., v. 2, p. 315324, 2001.

CASSELL, M.D.; WRIGHT, D.J. Topography of projections from the medial prefrontal cortex to the amygdala in the rat. Brain Res. Bull., v. 17, p. 321-333, 1986.

CASTNER, S.A.; WILLIAMS, G.V. Tuning the engine of cognition: a focus on NMDA/D1 receptor interactions in prefrontal cortex. Brain Cogn., v. 63, p. 94-122, 2007.

CECHETTO, D.F.; SAPER, C.B. Evidence for a viscerotopic sensory representation in the cortex and thalamus in the rat. J. Comp. Neurol., v. 262, p. 27-45, 1987.

CELIO, M.R. Calbindin D-28k and parvalbumin in the rat nervous system. Neuroscience, v. 35, p. 375-475, 1990.

CEPEDA, C.; BUCHWALD, N.A.; LEVINE, M.S. Neuromodulatory actions of dopamine in the neostriatum are dependent upon the excitatory amino acid receptor subtypes activated. Proc. Natl. Acad. Sci. U. S. A., v. 90, p. 9576-9580, 1993.

CEPEDA, C.; COLWELL, C.S.; ITRI, J.N.; CHANDLER, S.H.; LEVINE, M.S. Dopaminergic modulation of NMDA-induced whole cell currents in neostriatal neurons in slices: contribution of calcium conductances. J. Neurophysiol., v. 79, p. 82-94, 1998.

CEPEDA, C.; LEVINE, M.S. Dopamine and N-methyl-D-aspartate receptor interactions in the neostriatum. Dev. Neurosci., v. 20, p. 1-18, 1998.

CEPEDA, C.; LEVINE, M.S. Where do you think you are going? The NMDA-D1 receptor trap. Sci. STKE., v. 2006, p. pe20, 2006.

CEPEDA, C.; RADISAVLJEVIC, Z.; PEACOCK, W.; LEVINE, M.S.; BUCHWALD, N.A. Differential modulation by dopamine of responses evoked by excitatory amino acids in human cortex. Synapse, v. 11, p. 330-341, 1992.

CHEN, G.; GREENGARD, P.; YAN, Z. Potentiation of NMDA receptor currents by dopamine D1 receptors in prefrontal cortex. Proc. Natl. Acad. Sci. U. S. A., v. 101, p. 2596-2600, 2004.

CHEN, Q.; VEENMAN, L.; KNOPP, K.; YAN, Z.; MEDINA, L.; SONG, W.J.; SURMEIER, D.J.; REINER, A. Evidence for the preferential localization of glutamate receptor-1 subunits of AMPA receptors to the dendritic spines of medium spiny neurons in rat striatum. Neuroscience, v. 83, p. 749-761, 1998. 
CLEMENTS, J.D.; WESTBROOK, G.L. Activation kinetics reveal the number of glutamate and glycine binding sites on the N-methyl-D-aspartate receptor. Neuron, v. 7, p. 605-613, 1991.

COGNET, L.; GROC, L.; LOUNIS, B.; CHOQUET, D. Multiple routes for glutamate receptor trafficking: surface diffusion and membrane traffic cooperate to bring receptors to synapses. Sci. STKE., v. 2006, p. pe13, 2006.

CONDÉ, F.; MAIRE-LEPOIVRE, E.; AUDINAT, E.; CREPEL, F. Afferent connections of the medial frontal cortex of the rat. II. Cortical and subcortical afferents. J. Comp. Neurol , v. 352, p. 567-593, 1995.

CONTI, F.; BARBARESI, P.; MELONE, M.; DUCATI, A. Neuronal and glial localization of NR1 and NR2A/B subunits of the NMDA receptor in the human cerebral cortex. Cereb. Cortex, v. 9, p. 110-120, 1999.

CONTI, F.; MINELLI, A.; BRECHA, N.C. Cellular localization and laminar distribution of AMPA glutamate receptor subunits mRNAs and proteins in the rat cerebral cortex. J Comp. Neurol. , v. 350, p. 241-259, 1994.

CULL-CANDY, S., KELLY, L., FARRANT, M. Regulation of $\mathrm{Ca}^{2+}$-permeable AMPA receptors: synaptic plasticity and beyond. Curr. Opin Neurobiol., v. 16, p. 288-297.

CURTIS, D.R.; WATKINS J.C. The excitation and depression of spinal neurones by structurally related amino acids. J. Neurochem , v. 6, p. 117-141, 1960.

DAHLSTROEM, A.; FUXE, K. Evidence for the Existence of Monoamine-Containing Neurons in the Central Nervous System. I. Demonstration of Monoamines in the Cell Bodies of Brain Stem Neurons. Acta Physiol. Scand. Suppl., v. 232, p. 231-255, 1964.

DALLEY, J.W.; CARDINAL, R.N., ROBBINS, T.W. Prefrontal executive and cognitive functions in rodents: neural and neurochemical substrates. Neurosci. Biobehav. Rev., v. 28, p. 771-784, 2004.

DELATOUR, B.; WITTER, M.P. Projections from the parahippocampal region to the prefrontal cortex in the rat: evidence of multiple pathways. Eur. J. Neurosci., v. 15, p. 1400-1407, 2002.

DENG, Y.P.; XIE, J.P.; WANG, H.B.; LEI, W.L.; CHEN, Q.; REINER, A. Differential localization of the GluR1 and GluR2 subunits of the AMPA-type glutamate receptor among striatal neuron types in rats. J. Chem. Neuroanat., v. 33, p. 167-192, 2007.

DERKACH, V.A.; OH, M.C.; GUIRE, E.S.; SODERLING, T.R. Regulatory mechanisms of AMPA receptors in synaptic plasticity. Nat. Rev. Neurosci., v. 8, p. 101-113, 2007.

DEUTCH, A.Y. Prefrontal cortical dopamine systems and the elaboration of functional corticostriatal circuits: implications for schizophrenia and Parkinson's disease. J. Neural. Transm. Gen. Sect., v. 91, p. 197-221, 1993. 
DEUTCH, A.Y.; GOLDSTEIN, M.; BALDINO, F. JR.; ROTH, R.H. Telencephalic projections of the A8 dopamine cell group. Ann. N. Y. Acad. Sci., v. 537, p. 27-50, 1988.

DI CHIARA, G.; IMPERATO, A. Drugs abused by humans preferentially increase synaptic dopamine concentrations in the mesolimbic system of freely moving rats. Proc. Natl. Acad. Sci. U. S. A., v. 85, p. 5274-5278, 1988.

DINGLEDINE, R.; BORGES, K.; BOWIE, D.; TRAYNELIS, S.F. The glutamate receptor ion channels. Pharmacol. Rev., v. 51, p. 7-61, 1999.

DIVAC, I.; KOSMAL, A.; BJORKLUND, A.; LINDVALL, O. Subcortical projections to the prefrontal cortex in the rat as revealed by the horseradish peroxidase technique. Neuroscience, v. 3, p. 785-796, 1978.

DUNAH, A.W.; SIRIANNI, A.C.; FIENBERG, A.A.; BASTIA, E.; SCHWARZSCHILD, M.A.; STANDAERT, D.G. Dopamine D1-dependent trafficking of striatal N-methyl-Daspartate glutamate receptors requires Fyn protein tyrosine kinase but not DARPP32. Mol. Pharmacol., v. 65, p. 121-129, 2004.

DUNAH, A.W.; STANDAERT, D.G. Dopamine D1 receptor-dependent trafficking of striatal NMDA glutamate receptors to the postsynaptic membrane. J. Neurosci., v. 21, p. 5546-5558, 2001.

DURSTEWITZ, D.; SEAMANS, J.K. The computational role of dopamine D1 receptors in working memory. Neural Netw., v. 15, p. 561-572, 2002.

EHRINGER, H.; HORNYKIEWICZ, O. Verteilung von Noradrenalin und Dopamin (3Hydroxytyramin) im Gehirn des Menschen und ihr Verhalten bei Erkrankungen des Extrapyramidalen Systems. Klin. Wochenschr., v. 38, p. 1236-1239, 1960.

FALCK, B.; HILLARP, N.A.; THIEME, G.; TORP, A. Fluorescence of catechol amines and related compounds condensed with formaldehyde. Brain Res. Bull., v. 9, p. xi$\mathrm{xv}, 1982$.

FALLON, J.H. Collateralization of monoamine neurons: mesotelencephalic dopamine projections to caudate, septum, and frontal cortex. J. Neurosci., v. 1, p. 1361-1368, 1981.

FALLON, J.H.; LOUGHLIN, S.E. Monoamine innervation of the forebrain: collateralization. Brain Res. Bull., v. 9, p. 295-307, 1982.

FIENBERG, A.A.; HIROI, N.; MERMELSTEIN, P.G.; SONG, W.; SNYDER, G.L.; NISHI, A.; CHERAMY, A.; O'CALLAGHAN, J.P.; MILLER, D.B., COLE, D.G.; CORBETT, R.; HAILE, C.N.; COOPER, D.C.; ONN, S.P.; GRACE, A.A.; OUIMET, C.C.; WHITE, F.J.; HYMAN, S.E.; SURMEIER, D.J.; GIRAULT, J.; NESTLER, E.J.; GREENGARD, P. DARPP-32: regulator of the efficacy of dopaminergic neurotransmission. Science, v. 281, p. 838-842, 1998. 
FLORES-HERNANDEZ, J.; CEPEDA, C.; HERNANDEZ-ECHEAGARAY, E.; CALVERT, C.R.; JOKEL, E.S.; FIENBERG, A.A.; GREENGARD, P.; LEVINE, M.S. Dopamine enhancement of NMDA currents in dissociated medium-sized striatal neurons: role of D1 receptors and DARPP-32. J. Neurophysiol., v. 88, p. 30103020, 2002.

FLOYD, N.S.; PRICE, J.L.; FERRY, A.T.; KEAY, K.A.; BANDLER, R. Orbitomedial prefrontal cortical projections to hypothalamus in the rat. J. Comp. Neurol., v. 432, p. 307-328, 2001.

FOOTE, S.L.; BLOOM, F.E.; ASTON-JONES, G. Nucleus locus ceruleus: new evidence of anatomical and physiological specificity. Physiol. Rev., v. 63, p. 844914, 1983.

FREMEAU, R.T., JR.; TROYER, M.D.; PAHNER, I.; NYGAARD, G.O.; TRAN, C.H.; REIMER, R.J.; BELLOCCHIO, E.E.; FORTIN, D.; STORM-MATHISEN, J.; EDWARDS, R.H. The expression of vesicular glutamate transporters defines two classes of excitatory synapse. Neuron, v. 31, p. 247-260, 2001.

FREMEAU, R.T., JR.; VOGLMAIER, S.; SEAL, R.P.; EDWARDS, R.H. VGLUTs define subsets of excitatory neurons and suggest novel roles for glutamate. Trends Neurosci., v. 27, p. 98-103, 2004.

FREUND, T.F.; POWELL, J.F.; SMITH, A.D. Tyrosine hydroxylase-immunoreactive boutons in synaptic contact with identified striatonigral neurons, with particular reference to dendritic spines. Neuroscience, v. 13, p. 1189-1215, 1984.

FREY, U.; SCHROEDER, H.; MATTHIES, H. Dopaminergic antagonists prevent long-term maintenance of posttetanic LTP in the CA1 region of rat hippocampal slices. Brain Res., v. 522, p. 69-75, 1990.

FUSTER, J. M. The prefrontal cortex. Anatomy, physiology and neuropsychology of the frontal lobe. 3. ed. New York: Lippincott-Raven, 1997.

FUSTER, J.M. The prefrontal cortex-an update: time is of the essence. Neuron, v. 30, p. 319-333, 2001.

GAO, C.; WOLF, M.E. Dopamine receptors regulate NMDA receptor surface expression in prefrontal cortex neurons. J. Neurochem., v. 106, p. 2489-2501, 2008.

GABBOTT, P.L.; DICKIE, B.G.; VAID, R.R.; HEADLAM, A.J.; BACON, S.J. Localcircuit neurones in the medial prefrontal cortex (areas 25, 32 and 24b) in the rat: morphology and quantitative distribution. J. Comp. Neurol., v. 377, p. 465-499, 1997.

GABBOTT, P.; HEADLAM, A.; BUSBY, S. Morphological evidence that CA1 hippocampal afferents monosynaptically innervate PV-containing neurons and NADPH-diaphorase reactive cells in the medial prefrontal cortex (Areas 25/32) of the rat. Brain Res., v. 946, p. 314-322, 2002. 
GABBOTT, P. L.; WARNER, T. A.; JAYS, P. R.; SALWAY, P.; BUSBY, S. J. Prefrontal cortex in the rat: projections to subcortical autonomic, motor, and limbic centers. J. Comp. Neurol., v. 492, n. 2, p. 145-77, 2005.

GEFFARD, M.; BUIJS, R.M.; SEGUELA, P.; POOL, C.W.; LE MOAL, M. First demonstration of highly specific and sensitive antibodies against dopamine. Brain Res., v. 294, p. 161-165, 1984.

GEIGER, J.R.; MELCHER, T.; KOH, D.S.; SAKMANN, B.; SEEBURG, P.H.; JONAS, P.; MONYER, $\mathrm{H}$. Relative abundance of subunit mRNAs determines gating and $\mathrm{Ca2+}$ permeability of AMPA receptors in principal neurons and interneurons in rat CNS. Neuron, v. 15, p. 193-204, 1995.

GERFEN, C.R. The neostriatal mosaic: multiple levels of compartmental organization. J. Neural. Transm. Suppl., v. 36, p. 43-59, 1992.

GOLDMAN-RAKIC, P.S. Cellular and circuit basis of working memory in prefrontal cortex of nonhuman primates. Prog. Brain Res., v. 85, p. 325-336, 1990.

GOLDMAN-RAKIC, P.S. Cellular basis of working memory. Neuron, v. 14, p. 477485, 1995.

GOLDMAN-RAKIC, P.S. The physiological approach: functional architecture of working memory and disordered cognition in schizophrenia. Biol. Psychiatry, v. 46, p. 650-661, 1999.

GONCALVES, L.; NOGUEIRA, M.I.; SHAMMAH-LAGNADO, S.J.; METZGER, M. Prefrontal afferents to the dorsal raphe nucleus in the rat. Brain Res. Bull., v. 78, p. 240-247, 2009.

GONZALEZ-ALBO, M.C.; DEFELIPE, J. Colocalization of glutamate ionotropic receptor subunits in the human temporal neocortex. Cereb. Cortex, v. 10, p. 621$631,2000$.

GONZALEZ-ALBO, M.C.; ELSTON, G.N.; DEFELIPE, J. The human temporal cortex: characterization of neurons expressing nitric oxide synthase, neuropeptides and calcium-binding proteins, and their glutamate receptor subunit profiles. Cereb. Cortex, v. 11, p. 1170-1181, 2001.

GONZALEZ-ISLAS, C.; HABLITZ, J.J. Dopamine enhances EPSCs in layer II-III pyramidal neurons in rat prefrontal cortex. J. Neurosci., v. 23, p. 867-875, 2003.

GOTO, Y.; OTANI, S.; GRACE, A.A. The Yin and Yang of dopamine release: a new perspective. Neuropharmacology, v. 53, p. 583-587, 2007.

GREENGARD, P. The neurobiology of slow synaptic transmission. Science, v. 294, p. 1024-1030, 2001.

GREENGARD, P.; ALLEN, P.B.; NAIRN, A.C. Beyond the dopamine receptor: the DARPP-32/protein phosphatase-1 cascade. Neuron, v. 23, p. 435-447, 1999. 
GREENGARD, P.; NAIRN, A.C.; GIRAULT, J.A.; OUIMET, C.C.; SNYDER, G.L.; FISONE, G.; ALLEN, P.B.; FIENBERG, A.; NISHI, A. The DARPP-32/protein phosphatase-1 cascade: a model for signal integration. Brain Res. Brain Res. Rev., v. 26, p. 274-284, 1998.

GREGER, I.H.; ZIFF, E.B.; PENN, A.C. Molecular determinants of AMPA receptor subunit assembly. Trends Neurosci., v. 30, p. 407-416, 2007.

GROENEWEGEN, H.J. Organization of the afferent connections of the mediodorsal thalamic nucleus in the rat, related to the mediodorsal-prefrontal topography. Neuroscience, v. 24, p. 379-431, 1988.

GROENEWEGEN, H.J.; UYLINGS, H.B. The prefrontal cortex and the integration of sensory, limbic and autonomic information. Prog. Brain Res., v. 126, p. 3-28, 2000.

GURDEN, H.; TASSIN, J.P.; JAY, T.M. Integrity of the mesocortical dopaminergic system is necessary for complete expression of in vivo hippocampal-prefrontal cortex long-term potentiation. Neuroscience, v. 94, p. 1019-1027, 1999

GURDEN, H.; TAKITA, M.; JAY, T.M. Essential role of D1 but not D2 receptors in the NMDA receptor-dependent long-term potentiation at hippocampal-prefrontal cortex synapses in vivo. J. Neurosci., v. 20, p. RC106, 2000.

HABER, S.N.; FUDGE, J.L.; MCFARLAND, N.R. Striatonigrostriatal pathways in primates form an ascending spiral from the shell to the dorsolateral striatum. J. Neurosci., v. 20, p. 2369-2382, 2000.

HAKANSSON, K.; GALDI, S.; HENDRICK, J.; SNYDER, G.; GREENGARD, P.; FISONE, G. Regulation of phosphorylation of the GluR1 AMPA receptor by dopamine D2 receptors. J. Neurochem., v. 96, p. 482-488, 2006.

HALPAIN, S.; GIRAULT, J.A.; GREENGARD, P. Activation of NMDA receptors induces dephosphorylation of DARPP-32 in rat striatal slices. Nature, v. 343, p. 369372, 1990.

HAMILTON, K.A. Distribution of immunoreactivity for gamma-aminobutyric acid in the salamander olfactory bulb. J. Comp. Neurol., v. 319, p. 606-614, 1992.

HARKANY, T.; VARGA, C.; GROSCHE, J.; MULDER, J.; LUITEN, P.G.; HORTOBAGYI, T.; PENKE, B.; HARTIG, W. Distinct subsets of nucleus basalis neurons exhibit similar sensitivity to excitotoxicity. Neuroreport, v. 13, p. 767-772, 2002.

HAYASHI, T. Effects of sodium glutamate on the nervous system. Keio J. Méd., v. 3, p. 192-193, 1954.

HE, Y.; JANSSEN, W.G.; MORRISON, J.H. Synaptic coexistence of AMPA and NMDA receptors in the rat hippocampus: a postembedding immunogold study. $\mathbf{J}$. Neurosci. Res., v. 54, p. 444-449, 1998. 
HEIDBREDER, C.A.; GROENEWEGEN, H.J. The medial prefrontal cortex in the rat: evidence for a dorso-ventral distinction based upon functional and anatomical characteristics. Neurosci. Biobehav. Rev., v. 27, p. 555-579, 2003.

HEIMER, L.; VAN HOESEN, G.W. The limbic lobe and its output channels: implications for emotional functions and adaptive behavior. Neurosci. Biobehav. Rev., v. 30, p. 126-147, 2006.

HEMMINGS, H.C., JR.; GREENGARD, P. DARPP-32, a dopamine- and adenosine 3':5'-monophosphate-regulated phosphoprotein: regional, tissue, and phylogenetic distribution. J. Neurosci., v. 6, p. 1469-1481, 1986.

HEMMINGS, H.C., JR.; GREENGARD, P.; TUNG, H.Y.; COHEN, P. DARPP-32, a dopamine-regulated neuronal phosphoprotein, is a potent inhibitor of protein phosphatase-1. Nature, v. 310, p. 503-505, 1984.

HEMMINGS, H.C., JR.; NAIRN, A.C.; ASWAD, D.W.; GREENGARD, P. DARPP-32, a dopamine- and adenosine $3^{\prime}: 5^{\prime}$-monophosphate-regulated phosphoprotein enriched in dopamine-innervated brain regions. II. Purification and characterization of the phosphoprotein from bovine caudate nucleus. J. Neurosci., v. 4, p. 99-110, 1984.

HOF, P.R.; VISSAVAJJHALA, P.; ROSENTHAL, R.E.; FISKUM, G.; MORRISON, J.H. Distribution of glutamate receptor subunit proteins GluR2(4), GluR5/6/7, and NMDAR1 in the canine and primate cerebral cortex: a comparative immunohistochemical analysis. Brain Res., v. 723, p. 77-89, 1996.

HÖFKELT, T.; MARTENSSON, R.; BJÖRKLUND, A.; KLEINAU, S.; GOLDSTEIN, S. Distributional maps of tyrosine-hydroxylase-immunoreactive neurons in the rat brain. In: BJÖRKLUND A., HÖFKELT T. (Ed.). Handbook of Chemical Neuroanatomy. Amsterdam: Elsevier, 1984.Vol. 2, p. 277-379.

HOLLMANN, M.; HEINEMANN, S. CLONED GLUTAMATE RECEPTORS. Annu. Rev. Neurosci., v. 17, p. 31-108, 1994.

HOOVER, W.B.; VERTES, R.P. Anatomical analysis of afferent projections to the medial prefrontal cortex in the rat. Brain Struct. Funct., v. 212, p. 149-179, 2007.

HOTTE, M.; THUAULT, S.; DINELEY, K.T.; HEMMINGS, H.C., JR.; NAIRN, A.C.; JAY, T.M. Phosphorylation of CREB and DARPP-32 during late LTP at hippocampal to prefrontal cortex synapses in vivo. Synapse, v. 61, p. 24-28, 2007.

HUANG, Y.Y.; SIMPSON, E.; KELLENDONK, C.; KANDEL, E.R. Genetic evidence for the bidirectional modulation of synaptic plasticity in the prefrontal cortex by D1 receptors. Proc. Natl. Acad. Sci. U. S. A., v. 101, p. 3236-3241, 2004.

HUNTLEY, G.W.; ROGERS, S.W.; MORAN, T.; JANSSEN, W.; ARCHIN, N.; VICKERS, J.C.; CAULEY, K.; HEINEMANN, S.F.; MORRISON, J.H. Selective distribution of kainate receptor subunit immunoreactivity in monkey neocortex revealed by a monoclonal antibody that recognizes glutamate receptor subunits GluR5/6/7. J. Neurosci., v. 13, p. 2965-2981, 1993. 
HUNTLEY, G.W.; VICKERS, J.C.; JANSSEN, W.; BROSE, N.; HEINEMANN, S.F.; MORRISON, J.H. Distribution and synaptic localization of immunocytochemically identified NMDA receptor subunit proteins in sensory-motor and visual cortices of monkey and human. J. Neurosci., v. 14, p. 3603-3619, 1994.

HUNTLEY, G.W.; VICKERS, J.C.; MORRISON, J.H. Quantitative localization of NMDAR1 receptor subunit immunoreactivity in inferotemporal and prefrontal association cortices of monkey and human. Brain Res., v. 749, p. 245-262, 1997.

HURLEY, K.M.; HERBERT, H.; MOGA, M.M.; SAPER, C.B. Efferent projections of the infralimbic cortex of the rat. J. Comp. Neurol., v. 308, p. 249-276, 1991.

HYMAN, S.E.; MALENKA, R.C.; NESTLER, E.J. Neural mechanisms of addiction: the role of reward-related learning and memory. Annu. Rev. Neurosci., v. 29, p. 565-598, 2006

ISHII, T. et al. Molecular characterization of the family of the N-methyl-D-aspartate receptor subunits. J. Biol. Chem., v. 268, p. 2836-2843, 1993.

ITOH, K.; KONISHI, A.; NOMURA, S.; MIZUNO, N.; NAKAMURA, Y.; SUGIMOTO, T. Application of coupled oxidation reaction to electron microscopic demonstration of horseradish peroxidase: cobalt-glucose oxidase method. Brain Res., v. 175, p. 341346, 1979.

IVERSEN, S.D.; IVERSEN, L.L. Dopamine: 50 years in perspective. Trends Neurosci., v. 30, p. 188-193, 2007.

JAY, T.M. Dopamine: a potential substrate for synaptic plasticity and memory mechanisms. Prog. Neurobiol., v. 69, p. 375-390, 2003.

JAY, T.M.; WITTER, M.P. Distribution of hippocampal CA1 and subicular efferents in the prefrontal cortex of the rat studied by means of anterograde transport of Phaseolus vulgaris-leucoagglutinin. J. Comp. Neurol., v. 313, p. 574-586, 1991.

JENTSCH, J.D.; ROTH, R.H. The neuropsychopharmacology of phencyclidine: from NMDA receptor hypofunction to the dopamine hypothesis of schizophrenia. Neuropsychopharmacology, v. 20, p. 201-225, 1999.

KALIVAS, P.W. Glutamate systems in cocaine addiction. Curr. Opin. Pharmacol., v. 4, p. 23-29, 2004.

KALIVAS, P.W.; O'BRIEN, C. Drug addiction as a pathology of staged neuroplasticity. Neuropsychopharmacology, v. 33, p. 166-180, 2008.

KALIVAS, P.W.; VOLKOW, N.; SEAMANS, J. Unmanageable motivation in addiction: a pathology in prefrontal-accumbens glutamate transmission. Neuron, v. 45, p. 647650, 2005.

KALSBEEK, A.; VOORN, P.; BUIJS, R.M.; POOL, C.W.; UYLINGS, H.B. Development of the dopaminergic innervation in the prefrontal cortex of the rat. $\mathbf{J}$. Comp. Neurol., v. 269, p. 58-72, 1988. 
KANDEL, E.R. The molecular biology of memory storage: a dialogue between genes and synapses. Science, v. 294, p. 1030-1038, 2001.

KAUER, J.A.; MALENKA, R.C. Synaptic plasticity and addiction. Nat. Rev. Neurosci., v. 8, p. 844-858, 2007.

KAWAGUCHI, Y.; KONDO, S. Parvalbumin, somatostatin and cholecystokinin as chemical markers for specific GABAergic interneuron types in the rat frontal cortex. J. Neurocytol., v. 31, p. 277-287, 2002.

KEBABIAN, J.W.; CALNE, D.B. Multiple receptors for dopamine. Nature, v. 277, p. 93-96, 1979.

KEBABIAN, J.W.; PETZOLD, G.L.; GREENGARD, P. Dopamine-sensitive adenylate cyclase in caudate nucleus of rat brain, and its similarity to the "dopamine receptor". Proc. Natl. Acad. Sci. U. S. A., v. 69, p. 2145-2149, 1972.

KELLEY, A.E. Memory and addiction: shared neural circuitry and molecular mechanisms. Neuron, v. 44, p. 161-179, 2004.

KELLEY, A.E.; BERRIDGE, K.C. The neuroscience of natural rewards: relevance to addictive drugs. J. Neurosci., v. 22, p. 3306-3311, 2002.

KESNER, R.P. Subregional analysis of mnemonic functions of the prefrontal cortex in the rat. Psychobiology, v. 28, p. 219-228, 2000.

KEW, J.N.; KEMP, J.A. Ionotropic and metabotropic glutamate receptor structure and pharmacology. Psychopharmacology, Berl., v. 179, p. 4-29, 2005.

KEW, J.N.; KOESTER, A.; MOREAU, J.L.; JENCK, F.; OUAGAZZAL, A.M.; MUTEL, V.; RICHARDS, J.G.; TRUBE, G.; FISCHER, G.; MONTKOWSKI, A.; HUNDT, W.; REINSCHEID, R.K.; PAULY-EVERS, M.; KEMP, J.A.; BLUETHMANN, H. Functional consequences of reduction in NMDA receptor glycine affinity in mice carrying targeted point mutations in the glycine binding site. J. Neurosci., v. 20, p. 40374049, 2000.

KHARAZIA, V.N.; WENTHOLD, R.J.; WEINBERG, R.J. GluR1-immunopositive interneurons in rat neocortex. J. Comp Neurol., v. 368, p. 399-412, 1996.

KILLACKEY, H.P.; KORALEK, K.A.; CHIAIA, N.L.; RHODES, R.W. Laminar and areal differences in the origin of the subcortical projection neurons of the rat somatosensory cortex. J. Comp. Neurol., v. 282, p. 428-445, 1989.

KIM, E.; SHENG, M. PDZ domain proteins of synapses. Nat. Rev Neurosci., v. 5, p. 771-781, 2004.

KONDO, M.; SUMINO, R.; OKADO, H. Combinations of AMPA receptor subunit expression in individual cortical neurons correlate with expression of specific calciumbinding proteins. J. Neurosci., v. 17, p. 1570-1581, 1997. 
KRETTEK, J.E.; PRICE, J.L. The cortical projections of the mediodorsal nucleus and adjacent thalamic nuclei in the rat. J. Comp. Neurol., v. 171, p. 157-191, 1977a.

KRETTEK, J.E.; PRICE, J.L. Projections from the amygdaloid complex to the cerebral cortex and thalamus in the rat and cat. J. Comp. Neurol., v. 172, p. 687722, $1977 b$.

KRUSE, M.S.; PREMONT, J.; KREBS, M.O.; JAY, T.M. Interaction of dopamine D1 with NMDA NR1 receptors in rat prefrontal cortex. Eur. Neuropsychopharmacol., v. 19, p. 296-304, 2009.

KURODA, M.; MURAKAMI, K.; KISHI, K.; PRICE, J.L. Thalamocortical synapses between axons from the mediodorsal thalamic nucleus and pyramidal cells in the prelimbic cortex of the rat. J. Comp. Neurol., v. 356, p. 143-151, 1995.

KURYATOV, A.; LAUBE, B.; BETZ, H.; KUHSE, J. Mutational analysis of the glycinebinding site of the NMDA receptor: structural similarity with bacterial amino acidbinding proteins. Neuron, v. 12, p. 1291-1300, 1994.

KUTSUWADA, T. et al. Molecular diversity of the NMDA receptor channel. Nature, v. 358, p. 36-41, 1992.

LANGLEY, K.C.; BERGSON, C.; GREENGARD, P.; OUIMET, C.C. Co-localization of the D1 dopamine receptor in a subset of DARPP-32-containing neurons in rat caudate-putamen. Neuroscience, v. 78, p. 977-983, 1997.

LAROCHE, S.; DAVIS, S.; JAY, T.M. Plasticity at hippocampal to prefrontal cortex synapses: dual roles in working memory and consolidation. Hippocampus, v. 10, p. 438-446, 2000.

LARUELLE, M.; KEGELES, L.S.; ABI-DARGHAM, A. Glutamate, dopamine, and schizophrenia: from pathophysiology to treatment. Ann. N. Y. Acad. Sci., v. 1003, p. 138-158, 2003.

LAU, C.G.; ZUKIN, R.S. NMDA receptor trafficking in synaptic plasticity and neuropsychiatric disorders. Nat. Rev. Neurosci., v. 8, p. 413-426, 2007.

LAUBE, B.; HIRAI, H.; STURGESS, M.; BETZ, H.; KUHSE, J. Molecular determinants of agonist discrimination by NMDA receptor subunits: analysis of the glutamate binding site on the NR2B subunit. Neuron, v. 18, p. 493-503, 1997.

LEE, F.J.; XUE, S.; PEI, L.; VUKUSIC, B.; CHERY, N.; WANG, Y.; WANG, Y.T.; NIZNIK, H.B.; YU, X.M.; LIU, F. Dual regulation of NMDA receptor functions by direct protein-protein interactions with the dopamine D1 receptor. Cell, v. 111, p. 219-230, 2002.

LEE, H.S.; KIM, M.A.; WATERHOUSE, B.D. Retrograde double-labeling study of common afferent projections to the dorsal raphe and the nuclear core of the locus coeruleus in the rat. J. Comp. Neurol., v. 481, p. 179-193, 2005. 
LEONHARD, C.M. The prefrontal cortex of the rat. I. Cortical projections of the mediodorsal nucleus. II. Eferent connections. Brain Res., v. 12, p. 321-343, 1969.

LERANTH, C.; SZEIDEMANN, Z.; HSU, M.; BUZSAKI, G. AMPA receptors in the rat and primate hippocampus: a possible absence of GluR2/3 subunits in most interneurons. Neuroscience, v. 70, p. 631-652, 1996.

LEVEY, A.I. et al. Localization of D1 and D2 dopamine receptors in brain with subtype-specific antibodies. Proc. Natl. Acad. Sci. U. S. A., v. 90, p. 8861-8865, 1993.

LEVINE, M.S.; LI, Z.; CEPEDA, C.; CROMWELL, H.C.; ALTEMUS, K.L. Neuromodulatory actions of dopamine on synaptically-evoked neostriatal responses in slices. Synapse, v. 24, p. 65-78, 1996.

LIDOW, M.S.; GOLDMAN-RAKIC, P.S.; GALLAGER, D.W.; RAKIC, P. Distribution of dopaminergic receptors in the primate cerebral cortex: quantitative autoradiographic analysis using $[3 \mathrm{H}]$ raclopride, $[3 \mathrm{H}]$ spiperone and $[3 \mathrm{H}] \mathrm{SCH} 23390$. Neuroscience, v. 40, p. 657-671, 1991.

LUPPI, P. H.; ASTON-JONES, G.; AKAOKA, H.; CHOUVET, G.; JOUVET, M. Afferent projections to the rat locus coeruleus demonstrated by retrograde and anterograde tracing with cholera-toxin $B$ subunit and Phaseolus vulgarisleucoagglutinin. Neuroscience, v. 65, p. 119-60, 1995.

MALENKA, R.C.; NICOLL, R.A. Long-term potentiation--a decade of progress? Science, v. 285, p. 1870-1874, 1999.

MALENKA, R.C., BEAR, M.F. LTP and LTD: an embarrassment of riches. Neuron, v. 44, p. 5-21, 2004.

MAYER, M.L.; ARMSTRONG, N. Structure and function of glutamate receptor ion channels. Annu. Rev. Physiol., v. 66, p. 161-181, 2004.

MCBAIN, C.J.; MAYER, M.L. N-methyl-D-aspartic acid receptor structure and function. Physiol. Rev., v. 74, p. 723-760, 1994.

MCDONALD, A.J. Organization of amygdaloid projections to the mediodorsal thalamus and prefrontal cortex: a fluorescence retrograde transport study in the rat. J. Comp. Neurol., v. 262, p. 46-58, 1987.

MCDONALD, A.J. Organization of amygdaloid projections to the prefrontal cortex and associated striatum in the rat. Neuroscience, v. 44, p. 1-14, 1991.

MCDONALD, A.J. Cortical pathways to the mammalian amygdala. Prog. Neurobiol., v. 55, p. 257-332, 1998.

MCDONALD, A.J.; MASCAGNI, F.; GUO, L. Projections of the medial and lateral prefrontal cortices to the amygdala: a Phaseolus vulgaris leucoagglutinin study in the rat. Neuroscience, v. 71, p. 55-75, 1996. 
MCGEORGE, A.J.; FAULL, R.L.M. The organization of the projection from the cerebral cortex to the striatum in the rat. Neuroscience, v. 29, p. 503-537, 1989.

MCFARLAND, K.; LAPISH, C.C.; KALIVAS, P.W. Prefrontal glutamate release into the core of the nucleus accumbens mediates cocaine-induced reinstatement of drugseeking behavior. J. Neurosci., v. 23, p. 3531-3537, 2003.

MCFARLAND, K.; DAVIDGE, S.B.; LAPISH, C.C.; KALIVAS, P.W. Limbic and motor circuitry underlying footshock-induced reinstatement of cocaine-seeking behavior. J. Neurosci., v. 24, p. 1551-1560, 2004.

MEADOR-WOODRUFF, J.H.; KLEINMAN, J.E. Neurochemistry of schizophrenia: glutamatergic abnormalities. In: DAVIS K.L.; CHARNEY, D.; COYLE, J.T.; NEMEROFF, C. (Ed.). Neuropsychopharmacology: The fifth generation of progress. Philadelphia: Lippincott Williams \& Wilkins, 2002, p. 717-728.

MELTZER, H.Y.; STAHL, S.M. The dopamine hypothesis of schizophrenia: a review. Schizophr. Bull., v. 2, p. 19-76, 1976.

METZGER, M.; JIANG, S.; BRAUN, K. A quantitative immuno-electron microscopic study of dopamine terminals in forebrain regions of the domestic chick involved in filial imprinting. Neuroscience, v. 111, p. 611-623, 2002.

MISSALE, C.; NASH, S.R.; ROBINSON, S.W.; JABER, M.; CARON, M.G. Dopamine receptors: from structure to function. Physiol. Rev., v. 78, p. 189-225, 1998.

MOLNAR, Z.; CHEUNG, A.F. Towards the classification of subpopulations of layer V pyramidal projection neurons. Neurosci. Res., v. 55, p. 105-115, 2006.

MONYER, H.; BURNASHEV, N.; LAURIE, D.J.; SAKMANN, B.; SEEBURG, P.H. Developmental and regional expression in the rat brain and functional properties of four NMDA receptors. Neuron, v. 12, p. 529-540, 1994.

MONYER, H.; SPRENGEL, R.; SCHOEPFER, R.; HERB, A.; HIGUCHI, M.; LOMELI, H.; BURNASHEV, N.; SAKMANN, B.; SEEBURG, P.H. Heteromeric NMDA receptors: molecular and functional distinction of subtypes. Science, v. 256, p. 12171221, 1992.

MORRIS, B.J.; COCHRAN, S.M.; PRATT, J.A. PCP: from pharmacology to modelling schizophrenia. Curr. Opin. Pharmacol., v. 5, p. 101-106, 2005.

MULLEN, R.J.; BUCK, C.R.; SMITH, A.M. NeuN, a neuronal specific nuclear protein in vertebrates. Development, v. 116, p. 201-211, 1992.

MULLER, U.; VON CRAMON, D.Y.; POLLMANN, S. D1- versus D2-receptor modulation of visuospatial working memory in humans. J. Neurosci., v. 18, p. 27202728, 1998. 
MULY, E.C., 3RD; SZIGETI, K.; GOLDMAN-RAKIC, P.S. D1 receptor in interneurons of macaque prefrontal cortex: distribution and subcellular localization. J. Neurosci., v. 18, p. 10553-10565, 1998.

MUNOZ, A.; WOODS, T.M.; JONES, E.G. Laminar and cellular distribution of AMPA, kainate, and NMDA receptor subunits in monkey sensory-motor cortex. J. Comp. Neurol., v. 407, p. 472-490, 1999.

NEAFSEY, E.J. Prefrontal cortical control of the autonomic nervous system: anatomical and physiological observations. Prog. Brain. Res., v. 85, p. 147-165; discussion 165-146, 1990.

NEGYESSY, L.; GOLDMAN-RAKIC, P.S. Subcellular localization of the dopamine D2 receptor and coexistence with the calcium-binding protein neuronal calcium sensor-1 in the primate prefrontal cortex. J. Comp. Neurol., v. 488, p. 464-475, 2005.

NICOLA, S.M.; SURMEIER, J.; MALENKA, R.C. Dopaminergic modulation of neuronal excitability in the striatum and nucleus accumbens. Annu. Rev. Neurosci., v. 23 , p. 185-215, 2000.

NISHI, A.; SNYDER, G.L.; GREENGARD, P. Bidirectional regulation of DARPP-32 phosphorylation by dopamine. J. Neurosci., v. 17, p. 8147-8155, 1997.

NISHI, A.; SNYDER, G.L.; NAIRN, A.C.; GREENGARD, P. Role of calcineurin and protein phosphatase-2A in the regulation of DARPP-32 dephosphorylation in neostriatal neurons. J. Neurochem., v. 72, p. 2015-2021, 1999a.

NISHI, A.; SNYDER, G.L.; FIENBERG, A.A.; FISONE, G.; APERIA, A.; NAIRN, A.C.; GREENGARD, P. Requirement for DARPP-32 in mediating effect of dopamine D2 receptor activation. Eur. J. Neurosci., v. 11, p. 2589-2592, 1999 b.

NISHI, A.; BIBB, J.A.; MATSUYAMA, S.; HAMADA, M.; HIGASHI, H.; NAIRN, A.C.; GREENGARD, P. Regulation of DARPP-32 dephosphorylation at PKA- and Cdk5sites by NMDA and AMPA receptors: distinct roles of calcineurin and protein phosphatase-2A. J. Neurochem., v. 81, p. 832-841, 2002.

NISHI, A.; WATANABE, Y.; HIGASHI, H.; TANAKA, M.; NAIRN, A.C., GREENGARD, $P$. Glutamate regulation of DARPP-32 phosphorylation in neostriatal neurons involves activation of multiple signaling cascades. Proc. Natl. Acad. Sci. U. S. A., v. 102, p. 1199-1204, 2005.

NISHI, M.; HINDS, H.; LU, H.P.; KAWATA, M.; HAYASHI, Y. Motoneuron-specific expression of NR3B, a novel NMDA-type glutamate receptor subunit that works in a dominant-negative manner. J. Neurosci., v. 21, p. RC185, 2001.

NOWAK, L.; BREGESTOVSKI, P.; ASCHER, P.; HERBET, A.; PROCHIANTZ, A. Magnesium gates glutamate-activated channels in mouse central neurones. Nature, v. 307, p. 462-465, 1984. 
NUSSER, Z. AMPA and NMDA receptors: similarities and differences in their synaptic distribution. Curr. Opin. Neurobiol., v. 10, p. 337-341, 2000.

OTANI, S.; DANIEL, H.; ROISIN, M.P.; CREPEL, F. Dopaminergic modulation of long-term synaptic plasticity in rat prefrontal neurons. Cereb. Cortex, v. 13, p. 12511256, 2003.

OUIMET, C.C. DARPP-32, a dopamine and cyclic AMP-regulated phosphoprotein, is present in corticothalamic neurons of the rat cingulate cortex. Brain Res., v. 562, p. 85-92, 1991.

OUIMET, C.C.; GREENGARD, P. Distribution of DARPP-32 in the basal ganglia: an electron microscopic study. J. Neurocytol., v. 19, p. 39-52, 1990a.

OUIMET, C.C.; GREENGARD, P. Immunocytochemistry of neuronal phosphoproteins in dopaminoceptive brain regions. In: BJÖRKLUND A.; HÖFKELT T.; KUHAR M.J. (Ed.) Handbook of Chemical Neuroanatomy. Amsterdam: Elsevier, 1990b, Vol. 9, p. 505-538.

OUIMET, C.C.; LAMANTIA, A.S.; GOLDMAN-RAKIC, P.; RAKIC, P.; GREENGARD, P. Immunocytochemical localization of DARPP-32, a dopamine and cyclic-AMPregulated phosphoprotein, in the primate brain. J. Comp. Neurol., v. 323, p. 209218, 1992.

OUIMET, C.C.; LANGLEY-GULLION, K.C.; GREENGARD, P. Quantitative immunocytochemistry of DARPP-32-expressing neurons in the rat caudatoputamen. Brain Res., v. 808, p. 8-12, 1998.

OUIMET, C.C.; MILLER, P.E.; HEMMINGS, H.C., JR.; WALAAS, S.I.; GREENGARD, P. DARPP-32, a dopamine- and adenosine 3':5'-monophosphate-regulated phosphoprotein enriched in dopamine-innervated brain regions. III. Immunocytochemical localization. J. Neurosci., v. 4, p. 111-124, 1984.

PASPALAS, C.D.; GOLDMAN-RAKIC, P.S. Microdomains for dopamine volume neurotransmission in primate prefrontal cortex. J. Neurosci., v. 24, p. 5292-5300, 2004.

PASSINGHAM, R. The frontal lobes and voluntary action. Oxford: Oxford University Press, 1993.

PAXINOS, G.; WATSON, C. The rat brain in stereotaxic coordinates. New York: Academic Press, 1998.

PEI, L.; LEE, F.J.; MOSZCZYNSKA, A.; VUKUSIC, B.; LIU, F. Regulation of dopamine D1 receptor function by physical interaction with the NMDA receptors. J. Neurosci., v. 24, p. 1149-1158, 2004.

PEREZ, R.G.; LEWIS, R.M. Regional distribution of DARPP-32 (dopamine- and adenosine $3^{\prime}, 5$ '-monophosphate-regulated phosphoprotein of $\left.\mathrm{Mr}=32,000\right) \mathrm{mRNA}$ in mouse brain. J. Comp. Neurol., v. 318, p. 304-315, 1992. 
PETRALIA, R.S.; RUBIO, M.E.; WENTHOLD, R.J. Selectivity in the distribution of glutamate receptors in neurons. Cell. Biol. Int., v. 22, p. 603-608, 1998.

PETRALIA, R.S.; WANG, Y.X.; MAYAT, E.; WENTHOLD, R.J. Glutamate receptor subunit 2-selective antibody shows a differential distribution of calcium-impermeable AMPA receptors among populations of neurons. J. Comp. Neurol., v. 385, p. 456476, 1997.

PETRALIA, R.S.; WANG, Y.X.; WENTHOLD, R.J. The NMDA receptor subunits NR2A and NR2B show histological and ultrastructural localization patterns similar to those of NR1. J. Neurosci., v. 14, p. 6102-6120, 1994 a.

PETRALIA, R.S.; WANG, Y.X.; WENTHOLD, R.J. Histological and ultrastructural localization of the kainate receptor subunits, KA2 and GluR6/7, in the rat nervous system using selective antipeptide antibodies. J. Comp. Neurol., v. 349, p. 85-110, 1994b.

PETRALIA, R.S.; WENTHOLD, R.J. Light and electron immunocytochemical localization of AMPA-selective glutamate receptors in the rat brain. J. Comp. Neurol., v. 318, p. 329-354, 1992.

PETROVICH, G.D.; RISOLD, P.Y.; SWANSON, L.W. Organization of projections from the basomedial nucleus of the amygdala: a PHAL study in the rat. J. Comp. Neurol., v. 374, p. 387-420, 1996.

PEYRON, C.; PETIT, J. M.; RAMPON, C.; JOUVET, M.; LUPPI, P. H. Forebrain afferents to the rat dorsal raphe nucleus demonstrated by retrograde and anterograde tracing methods. Neuroscience, v. 82, p. 443-68, 1998.

PIN, J.P.; GALVEZ, T.; PREZEAU, L. Evolution, structure, and activation mechanism of family 3/C G-protein-coupled receptors. Pharmacol. Ther., v. 98, p. 325-354, 2003.

PRALONG, E.; MAGISTRETTI, P.; STOOP, R. Cellular perspectives on the glutamate-monoamine interactions in limbic lobe structures and their relevance for some psychiatric disorders. Prog. Neurobiol., v. 67, p. 173-202, 2002.

PREUSS, T.M. Do rats have a prefrontal cortex? The Rose-Woolsey-Akert program reconsidered. J. Cogn. Neurosci., v. 7, p. 1-24.

RAY, J.P.; PRICE, J.L. The organization of the thalamocortical connections of the mediodorsal thalamic nucleus in the rat, related to the ventral forebrain-prefrontal cortex topography. J. Comp. Neurol., v. 323, p. 167-197, 1992.

RAY, J.P.; RUSSCHEN, F.T.; FULLER, T.A.; PRICE, J.L. Sources of presumptive glutamatergic/aspartatergic afferents to the mediodorsal nucleus of the thalamus in the rat. J. Comp. Neurol., v. 320, p. 435-456, 1992. 
REEP, R.L.; GOODWIN, G.S.; CORWIN, J.V. Topographic organization in the corticocortical connections of medial agranular cortex in rats. J. Comp. Neurol., v. 294, p. 262-280, 1990.

REEP, R.L.; CHEATWOOD, J.L.; CORWIN, J.V. The associative striatum: Organization of cortical projections to the dorsocentral striatum in rats. J. Comp. Neurol., v. 467, p. 271-292, 2003.

REPOVS, G.; BADDELEY, A. The multi-component model of working memory: explorations in experimental cognitive psychology. Neuroscience, v. 139, p. 5-21, 2006.

ROSE, J.E.; WOOLSEY, C.N. The orbitofrontal cortex and its connections with the mediodorsal nucleus in rabbit, sheep and cat. Res. Publ. Assoc. Res. Nerv. Ment. Dis., v. 27, p. 210-232, 1948.

ROTARU, D.C.; BARRIONUEVO, G.; SESACK, S.R. Mediodorsal thalamic afferents to layer III of the rat prefrontal cortex: synaptic relationships to subclasses of interneurons. J. Comp. Neurol., v. 490, p. 220-238, 2005.

RUDOLF, G.D.; CRONIN, C.A.; LANDWEHRMEYER, G.B.; STANDAERT, D.G.; PENNEY, J.B., JR.; YOUNG, A.B. Expression of N-methyl-D-aspartate glutamate receptor subunits in the prefrontal cortex of the rat. Neuroscience, v. 73, p. 417-427, 1996.

SANO, I.; GAMO, T.; KAKIMOTO, Y.; TANIGUCHI, K.; TAKESADA, M.; NISHINUMA, K. Distribution of catechol compounds in human brain. Biochim. Biophys. Acta, v. 32, p. 586-587, 1959.

SANTANA, N.; MENGOD, G.; ARTIGAS, F. Quantitative analysis of the expression of dopamine D1 and D2 receptors in pyramidal and GABAergic neurons of the rat prefrontal cortex. Cereb. Cortex, v. 19, p. 849-860, 2009.

SARANTIS, K.; MATSOKIS, N.; ANGELATOU, F. Synergistic interactions of dopamine D1 and glutamate NMDA receptors in rat hippocampus and prefrontal cortex: Involvement of ERK1/2 signaling. Neuroscience, 2009. In press.

SASAKI, Y.F.; ROTHE, T.; PREMKUMAR, L.S.; DAS, S.; CUI, J.; TALANTOVA, M.V.; WONG, H.K.; GONG, X.; CHAN, S.F.; ZHANG, D.; NAKANISHI, N.; SUCHER, N.J.; LIPTON, S.A. Characterization and comparison of the NR3A subunit of the NMDA receptor in recombinant systems and primary cortical neurons. $\mathbf{J}$. Neurophysiol., v. 87, p. 2052-2063, 2002.

SAPER, C.B. Organization of cerebral cortical afferent systems in the rat. II. Magnocellular basal nucleus. J. Comp. Neurol., v. 222, p. 313-342, 1984.

SAPER, C.B. Organization of cerebral cortical afferent systems in the rat. II. Hypothalamocortical projections. J. Comp. Neurol., v. 237, p. 21-46, 1985. 
SATOH, K.; FIBIGER, H.C. Cholinergic neurons of the laterodorsal tegmental nucleus: efferent and afferent connections. J. Comp. Neurol., v. 253, p. 277-302, 1986.

SAWAGUCHI, T.; GOLDMAN-RAKIC, P.S. D1 dopamine receptors in prefrontal cortex: involvement in working memory. Science, v. 251, p. 947-950, 1991.

SCHACTER, D.L.; TULVING, E. Memory systems 1994. Cambridge, Mass: MIT Press, 1994.

SCHALLING, M.; DJURFELDT, M.; HOKFELT, T.; EHRLICH, M.; KURIHARA, T.; GREENGARD, P. Distribution and cellular localization of DARPP-32 mRNA in rat brain. Brain Res. Mol. Brain Res., v. 7, p. 139-149, 1990.

SCHNABEL, R.; METZGER, M.; JIANG, S.; HEMMINGS, H.C., JR.; GREENGARD, P.; BRAUN, K. Localization of dopamine D1 receptors and dopaminoceptive neurons in the chick forebrain. J. Comp. Neurol., v. 388, p. 146-168, 1997.

SCHORGE, S.; COLQUHOUN, D. Studies of NMDA receptor function and stoichiometry with truncated and tandem subunits. J. Neurosci., v. 23, p. 1151-1158, 2003.

SCHULTZ, W. Behavioral dopamine signals. Trends Neurosci., v. 30, p. 203-210, 2007.

SCOTT, L.; APERIA, A. Interaction between N-methyl-d-aspartic acid receptors and D1 dopamine receptors: An important mechanism for brain plasticity. Neuroscience, v. 158, p. 62-66, 2009.

SCOTT, L.; KRUSE, M.S.; FORSSBERG, H.; BRISMAR, H.; GREENGARD, P.; APERIA, A. Selective up-regulation of dopamine D1 receptors in dendritic spines by NMDA receptor activation. Proc. Natl. Acad. Sci. U. S. A., v. 99, p. 1661-1664, 2002.

SCOTT, L.; ZELENIN, S.; MALMERSJO, S.; KOWALEWSKI, J.M.; MARKUS, E.Z.; NAIRN, A.C.; GREENGARD, P.; BRISMAR, H.; APERIA, A. Allosteric changes of the NMDA receptor trap diffusible dopamine 1 receptors in spines. Proc. Natl. Acad. Sci. U. S. A., v. 103, p. 762-767, 2006.

SEAMANS, J.K.; YANG, C.R. The principal features and mechanisms of dopamine modulation in the prefrontal cortex. Prog. Neurobiol., v. 74, p. 1-58, 2004.

SEAMANS, J.K.; DURSTEWITZ, D.; CHRISTIE, B.R.; STEVENS, C.F.; SEJNOWSKI, T.J. Dopamine D1/D5 receptor modulation of excitatory synaptic inputs to layer V prefrontal cortex neurons. Proc. Natl. Acad. Sci. U. S. A., v. 98, p. 301306, 2001.

SEEBURG, P.H.; HARTNER, J. Regulation of ion channel/neurotransmitter receptor function by RNA editing. Curr. Opin. Neurobiol., v. 13, p. 279-283, 2003. 
SEEMAN, P.; LEE, T. Antipsychotic drugs: direct correlation between clinical potency and presynaptic action on dopamine neurons. Science, v. 188, p. 1217-1219, 1975.

SESACK, S.R.; CARR, D.B.; OMELCHENKO, N.; PINTO, A. Anatomical substrates for glutamate-dopamine interactions: evidence for specificity of connections and extrasynaptic actions. Ann. N. Y. Acad. Sci., v. 1003, p. 36-52, 2003.

SESACK, S.R.; DEUTCH, A.Y.; ROTH, R.H.; BUNNEY, B.S. Topographical organization of the efferent projections of the medial prefrontal cortex in the rat: an anterograde tract-tracing study with Phaseolus vulgaris leucoagglutinin. J. Comp. Neurol., v. 290, p. 213-242, 1989.

SESACK, S.R.; SNYDER, C.L.; LEWIS, D.A. Axon terminals immunolabeled for dopamine or tyrosine hydroxylase synapse on GABA-immunoreactive dendrites in rat and monkey cortex. J. Comp. Neurol., v. 363, p. 264-280, 1995.

SHEPHERD, J.D.; HUGANIR, R.L. The cell biology of synaptic plasticity: AMPA receptor trafficking. Annu. Rev. Cell Dev. Biol., v. 23, p. 613-643, 2007.

SIEGEL, S.J.; BROSE, N.; JANSSEN, W.G.; GASIC, G.P.; JAHN, R.; HEINEMANN, S.F.; MORRISON, J.H. Regional, cellular, and ultrastructural distribution of N-methylD-aspartate receptor subunit 1 in monkey hippocampus. Proc. Natl. Acad. Sci. U. S. A., v. 91 , p. 564-568, 1994.

SMILEY, J.F.; GOLDMAN-RAKIC, P.S. Heterogeneous targets of dopamine synapses in monkey prefrontal cortex demonstrated by serial section electron microscopy: a laminar analysis using the silver-enhanced diaminobenzidine sulfide (SEDS) immunolabeling technique. Cereb. Cortex, v. 3, p. 223-238, 1993.

SMILEY, J.F.; WILLIAMS, S.M.; SZIGETI, K.; GOLDMAN-RAKIC, P.S. Light and electron microscopic characterization of dopamine-immunoreactive axons in human cerebral cortex. J. Comp. Neurol., v. 321, p. 325-335, 1992.

SMILEY, J.F.; LEVEY, A.I.; CILIAX, B.J.; GOLDMAN-RAKIC, P.S. D1 dopamine receptor immunoreactivity in human and monkey cerebral cortex: predominant and extrasynaptic localization in dendritic spines. Proc. Natl. Acad. Sci. U. S. A., v. 91, p. 5720-5724, 1994.

SMITH, A.D.; BOLAM, J.P. The neural network of the basal ganglia as revealed by the study of synaptic connections of identified neurones. Trends Neurosci., v. 13, p. 259-265, 1990.

SMITH, Y.; BEVAN, M.D.; SHINK, E.; BOLAM, J.P. Microcircuitry of the direct and indirect pathways of the basal ganglia. Neuroscience, v. 86, p. 353-387, 1998.

SNYDER, G.L.; ALLEN, P.B.; FIENBERG, A.A.; VALLE, C.G.; HUGANIR, R.L.; NAIRN, A.C.; GREENGARD, P. Regulation of phosphorylation of the GluR1 AMPA receptor in the neostriatum by dopamine and psychostimulants in vivo. J. Neurosci., v. 20 , p. $4480-4488,2000$. 
SNYDER, G.L.; GIRAULT, J.A.; CHEN, J.Y.; CZERNIK, A.J.; KEBABIAN, J.W.; NATHANSON, J.A.; GREENGARD, P. Phosphorylation of DARPP-32 and protein phosphatase inhibitor-1 in rat choroid plexus: regulation by factors other than dopamine. J. Neurosci., v. 12, p. 3071-3083, 1992.

SPANAGEL, R.; WEISS, F. The dopamine hypothesis of reward: past and current status. Trends Neurosci., v. 22, p. 521-527, 1999.

SPANO, P.F.; GOVONI, S.; TRABUCCHI, M. Studies on the pharmacological properties of dopamine receptors in various areas of the central nervous system. Adv. Biochem. Psychopharmacol., v. 19, p. 155-165, 1978.

STONE, J.M.; MORRISON, P.D.; PILOWSKY, L.S. Glutamate and dopamine dysregulation in schizophrenia--a synthesis and selective review. J. Psychopharmacol., v. 21, p. 440-452, 2007.

STORM-MATHISEN, J.; LEKNES, A.K.; BORE, A.T.; VAALAND, J.L.; EDMINSON, P.; HAUG, F.M.; OTTERSEN, O.P. First visualization of glutamate and GABA in neurones by immunocytochemistry. Nature, v. 301, p. 517-520, 1983.

SUN, X.; ZHAO, Y.; WOLF, M.E. Dopamine receptor stimulation modulates AMPA receptor synaptic insertion in prefrontal cortex neurons. J. Neurosci., v. 25, p. 73427351, 2005.

SURMEIER, D.J.; SONG, W.J.; YAN, Z. Coordinated expression of dopamine receptors in neostriatal medium spiny neurons. J. Neurosci., v. 16, p. 6579-6591, 1996.

SVENNINGSSON, P.; NISHI, A.; FISONE, G.; GIRAULT, J.A.; NAIRN, A.C.; GREENGARD, P. DARPP-32: an integrator of neurotransmission. Annu. Rev. Pharmacol. Toxicol., v. 44, p. 269-296, 2004.

SVENNINGSSON, P.; TZAVARA, E.T.; LIU, F.; FIENBERG, A.A.; NOMIKOS, G.G.; GREENGARD, P. DARPP-32 mediates serotonergic neurotransmission in the forebrain. Proc. Natl. Acad. Sc.i U. S. A., v. 99, p. 3188-3193, 2002.

SWANSON, L.W. A direct projection from Ammon's horn to prefrontal cortex in the rat. Brain Res., v. 217, p. 150-154, 1981.

SWANSON, L.W. The projections of the ventral tegmental area and adjacent regions: a combined fluorescent retrograde tracer and immunofluorescence study in the rat. Brain Res. Bull., v. 9, p. 321-353, 1982.

TAKAMORI, S.; RHEE, J.S.; ROSENMUND, C.; JAHN, R. Identification of differentiation-associated brain-specific phosphate transporter as a second vesicular glutamate transporter (VGLUT2). J. Neurosci., v. 21, p. RC182, 2001.

THIERRY, A.M.; BLANC, G.; SOBEL, A.; STINUS, L.; GOLWINSKI, J. Dopaminergic terminals in the rat cortex. Science, v. 182, p. 499-501, 1973. 
TSENG, K.Y.; O'DONNELL, P. Dopamine-glutamate interactions controlling prefrontal cortical pyramidal cell excitability involve multiple signaling mechanisms. J. Neurosci., v. 24, p. 5131-5139, 2004.

UNGLESS, M.A. Dopamine: the salient issue. Trends Neurosci., v. 27, p. 702-706, 2004.

UYLINGS, H.B.; GROENEWEGEN, H.J.; KOLB, B. Do rats have a prefrontal cortex? Behav. Brain Res., v. 146, p. 3-17, 2003.

UYLINGS, H.B.; VAN EDEN, C.G. Qualitative and quantitative comparison of the prefrontal cortex in rat and in primates, including humans. Prog. Brain Res., v. 85, p. 31-62, 1990.

VAN DE WERD, H.J.; UYLINGS, H.B. The rat orbital and agranular insular prefrontal cortical areas: a cytoarchitectonic and chemoarchitectonic study. Brain Struct. Funct., v. 212, p. 387-401, 2008.

VAN DER WERF, Y.D.; WITTER, M.P.; GROENEWEGEN, H.J. The intralaminar and midline nuclei of the thalamus. Anatomical and functional evidence for participation in processes of arousal and awareness. Brain Res. Brain Res. Rev., v. 39, p. 107-140, 2002.

VAN EDEN, C.G.; HOORNEMAN, E.M.; BUIJS, R.M.; MATTHIJSSEN, M.A.; GEFFARD, M.; UYLINGS, H.B. Immunocytochemical localization of dopamine in the prefrontal cortex of the rat at the light and electron microscopical level. Neuroscience, v. 22, p. 849-862, 1987.

VAN EDEN, C.G.; LAMME, V.A.; UYLINGS, H.B. Heterotopic Cortical Afferents to the Medial Prefrontal Cortex in the Rat. A Combined Retrograde and Anterograde Tracer Study. Eur. J. Neurosci., v. 4, p. 77-97, 1992.

VAN EDEN, C.G.; UYLINGS, H.B. Cytoarchitectonic development of the prefrontal cortex in the rat. J. Comp. Neurol., v. 241, p. 253-267, 1985.

VERTES, R.P. Analysis of projections from the medial prefrontal cortex to the thalamus in the rat, with emphasis on nucleus reuniens. J. Comp. Neurol., v. 442, p. 163-187, 2002.

VERTES, R.P. Differential projections of the infralimbic and prelimbic cortex in the rat. Synapse, v. 51, p. 32-58, 2004.

VERTES, R.P.; HOOVER, W.B.; DO VALLE, A.C.; SHERMAN, A.; RODRIGUEZ, J.J. Efferent projections of reuniens and rhomboid nuclei of the thalamus in the rat. $\mathbf{J}$. Comp. Neurol., v. 499, p. 768-796, 2006.

VERTES, R. P. A PHA-L analysis of ascending projections of the dorsal raphe nucleus in the rat. J. Comp. Neurol., v. 313, p. 643-68, 1991. 
VERTES, R.P.; HOOVER, W.B.; SZIGETI-BUCK, K.; LERANTH, C. Nucleus reuniens of the midline thalamus: link between the medial prefrontal cortex and the hippocampus. Brain Res. Bull, v. 71, p. 601-609, 2007.

VICKERS, J.C.; HUNTLEY, G.W.; EDWARDS, A.M.; MORAN, T.; ROGERS, S.W.; HEINEMANN, S.F.; MORRISON, J.H. Quantitative localization of AMPA/kainate and kainate glutamate receptor subunit immunoreactivity in neurochemically identified subpopulations of neurons in the prefrontal cortex of the macaque monkey. $\mathbf{J}$. Neurosci., v. 13, p. 2982-2992, 1993.

VISSAVAJJHALA, P.; JANSSEN, W.G.; HU, Y.; GAZZALEY, A.H.; MORAN, T.; HOF, P.R.; MORRISON, J.H. Synaptic distribution of the AMPA-GluR2 subunit and its colocalization with calcium-binding proteins in rat cerebral cortex: an immunohistochemical study using a GluR2-specific monoclonal antibody. Exp. Neurol., v. 142, p. 296-312, 1996.

WAFFORD, K.A.; KATHORIA, M.; BAIN, C.J.; MARSHALL, G.; LE BOURDELLES, B.; KEMP, J.A.; WHITING, P.J. Identification of amino acids in the N-methyl-Daspartate receptor NR1 subunit that contribute to the glycine binding site. Mol. Pharmacol., v. 47, p. 374-380, 1995.

WALAAS, S.I.; ASWAD, D.W.; GREENGARD, P. A dopamine- and cyclic AMPregulated phosphoprotein enriched in dopamine-innervated brain regions. Nature, v. 301, p. 69-71, 1983.

WALAAS, S.I.; GREENGARD, P. DARPP-32, a dopamine- and adenosine 3':5'monophosphate-regulated phosphoprotein enriched in dopamine-innervated brain regions. I. Regional and cellular distribution in the rat brain. J. Neurosci., v. 4, p. 8498, 1984.

WANG, H.; PICKEL, V.M. Dopamine D2 receptors are present in prefrontal cortical afferents and their targets in patches of the rat caudate-putamen nucleus. J. Comp. Neurol., v. 442, p. 392-404, 2002.

WANG, J.; O'DONNELL, P. D(1) dopamine receptors potentiate nmda-mediated excitability increase in layer $\mathrm{V}$ prefrontal cortical pyramidal neurons. Cereb. Cortex, v. 11 , p. $452-462,2001$.

WANG, W.W.; CAO, R.; RAO, Z.R.; CHEN, L.W. Differential expression of NMDA and AMPA receptor subunits in DARPP-32-containing neurons of the cerebral cortex, hippocampus and neostriatum of rats. Brain Res., v. 998, p. 174-183, 2004.

WATKINS, J.C.; JANE, D.E. The glutamate story. B. J. Pharmacol., v. 147, p. S100108, 2006. Suppl 1.

WEINBERGER, D.R.; BERMAN, K.F.; ILLOWSKY, B.P. Physiological dysfunction of dorsolateral prefrontal cortex in schizophrenia. III. A new cohort and evidence for a monoaminergic mechanism. Arch. Gen. Psychiatry, v. 45, p. 609-615, 1988. 
WERKMAN, T.R.; GLENNON, J.C.; WADMAN, W.J.; MCCREARY, A.C. Dopamine receptor pharmacology: interactions with serotonin receptors and significance for the aetiology and treatment of schizophrenia. CNS Neurol. Disord. Drug Targets, v. 5, p. 3-23, 2006.

WEST, A.R.; GRACE, A.A. Opposite influences of endogenous dopamine D1 and D2 receptor activation on activity states and electrophysiological properties of striatal neurons: studies combining in vivo intracellular recordings and reverse microdialysis. J. Neurosci., v. 22, p. 294-304, 2002.

WEST, A.R.; FLORESCO, S.B.; CHARARA, A.; ROSENKRANZ, J.A.; GRACE, A.A. Electrophysiological interactions between striatal glutamatergic and dopaminergic systems. Ann N. Y. Acad Sci., v. 1003, p. 53-74, 2003.

WILLIAMS, G.V.; GOLDMAN-RAKIC, P.S. Modulation of memory fields by dopamine D1 receptors in prefrontal cortex. Nature, v. 376, p. 572-575, 1995.

WILLIAMS, G.V.; CASTNER, S.A. Under the curve: critical issues for elucidating D1 receptor function in working memory. Neuroscience, v. 139, p. 263-276, 2006.

WILLIAMS, S.M.; GOLDMAN-RAKIC, P.S. Widespread origin of the primate mesofrontal dopamine system. Cereb. Cortex, v. 8, p. 321-345, 1998.

WILSON, C.J.; KAWAGUCHI, Y. The origins of two-state spontaneous membrane potential fluctuations of neostriatal spiny neurons. J. Neurosci., v. 16, p. 2397-2410, 1996.

WINTERER, G.; WEINBERGER, D.R. Genes, dopamine and cortical signal-to-noise ratio in schizophrenia. Trends Neurosci., v. 27, p. 683-690, 2004.

WISE, S.P. Forward frontal fields: phylogeny and fundamental function. Trends Neurosci., v. 31, p. 599-608, 2008.

WOLF, M.E.; SUN, X.; MANGIAVACCHI, S.; CHAO, S.Z. Psychomotor stimulants and neuronal plasticity. Neuropharmacology, v. 47 Suppl 1, p. 61-79, 2004.

WOLLMUTH, L.P.; SOBOLEVSKY, A.I. Structure and gating of the glutamate receptor ion channel. Trends Neurosci., v. 27, p. 321-328, 2004.

WOLLMUTH, L.P.; KUNER, T.; SAKMANN, B. Adjacent asparagines in the NR2subunit of the NMDA receptor channel control the voltage-dependent block by extracellular Mg2+. J. Physiol., v. 506, p. 13-32, 1998.

WONG, A.C.; SHETREAT, M.E.; CLARKE, J.O.; RAYPORT, S. D1- and D2-like dopamine receptors are co-localized on the presynaptic varicosities of striatal and nucleus accumbens neurons in vitro. Neuroscience, v. 89, p. 221-233, 1999. 
WRIGHT, C.I.; GROENEWEGEN, H.J. Patterns of convergence and segregation in the medial nucleus accumbens of the rat: relationships of prefrontal cortical, midline thalamic, and basal amygdaloid afferents. J. Comp. Neurol., v. 361, p. 383-403, 1995.

YANG, C.R.; CHEN, L. Targeting prefrontal cortical dopamine D1 and N-methyl-Daspartate receptor interactions in schizophrenia treatment. Neuroscientist, v. 11, p. 452-470, 2005.

YUNG, K.K.; BOLAM, J.P.; SMITH, A.D.; HERSCH, S.M.; CILIAX, B.J.; LEVEY, A.I. Immunocytochemical localization of D1 and D2 dopamine receptors in the basal ganglia of the rat: light and electron microscopy. Neuroscience, v. 65, p. 709-730, 1995. 